\title{
DESEMPENHO DE EDIFÍCIOS ALTOS COM EMPREGO DA INTERAÇÃO SOLO-ESTRUTURA
}

\author{
PERFORMANCE OF TALL BUILDINGS WITH EMPLOYMENT OF SOIL-STRUCTURE \\ INTERACTION
}

\author{
(1D) Gabriela de Athayde Duboc Bahia 1 \\ (D) Renato Pinto da Cunha ${ }^{2}$ \\ (D) Neusa Maria Bezerra Mota ${ }^{3}$ \\ ${ }^{1}$ Centro Universitário de Brasília, Brasília, \\ DF, Brasil, gabriela.bahia@ceub.edu.br \\ ${ }^{2}$ Universidade de Brasília, Brasília, DF, \\ Brasil, rpcunha@unb.br \\ ${ }^{3}$ Centro Universitário de Brasília, DF, Brasil, \\ neusa.mota@ceub.edu.br
}

Contribuição dos autores:

GADB: conceituação, curadoria de dados, análise formal, investigação, metodologia, visualização, escrita - rascunho original. RPC: conceituação, análise formal, investigação, metodologia, administração de projetos, recursos, supervisão, validação, escrita - revisão e edição. NMBM: conceituação, análise formal, investigação, metodologia, administração de projetos, supervisão, validação, visualização, escrita - revisão e edição.

Fomento: Conselho Nacional de Desenvolvimento Científico e Tecnológico Declaração de conflito: declara não haver

Editor Responsável:

Regina Coeli Ruschel $\mathbb{D}$

\begin{abstract}
Resumo
Este trabalho apresentou como objetivo verificar a influência da interação solo-estrutura (ISE) em um edifício alto por meio de um processo iterativo entre os programas CAD/TQS e GARP realizado no trabalho de Bahia (2015). Para isso, escolheu-se uma edificação residencial, localizada em Águas Claras/DF, com dados de controle de recalques e provas de carga. Iniciou-se a modelagem da estrutura, com a utilização do programa CAD/TQS, considerando os apoios indeslocáveis. Com os resultados dos esforços obtidos foram calculados os recalques das fundações por meio do software GARP. Em seguida, procedeu-se a retroanálise dos esforços da estrutura, flexibilizando os apoios com os dados de recalque obtidos pelo GARP. Esta iteração foi realizada até que a convergência dos resultados de carregamento e recalque fosse alcançada. Os efeitos do ISE foram verificados para os primeiros andares do edifício. As maiores variações foram do esforço normal ( $\mathrm{Fz})$ de $0,7 \mathrm{kN}$ no $\mathrm{P} 216$ ao final do $2^{\circ}$ pavimento; do momento em x (Mx) de -118,3 kN.m no P216 ao final do $1^{\circ}$ pavimento; do momento em y (My) de $-0,7 \mathrm{kN} . \mathrm{m}$ no $\mathrm{P} 221$ ao final do $1^{\circ}$ pavimento. No caso dos recalques, os resultados se aproximaram mais aos do monitoramento de recalques após a ISE, porém a média da variação relativa ainda foi alta, atingindo $-38,9 \%$. Os resultados se mostraram satisfatórios, visto que pesquisas recentes têm apresentado diminuição de recalques, considerando a ISE, e aumento dos esforços.
\end{abstract}

Palavras-chave: Interação solo-estrutura. Esforços atuantes. Fundações profundas.

\begin{abstract}
This work aims to verify soil-structure interaction (SSI) influence in a high building employing iterative process between CAD/TQS and GARP programs carried out by Bahia (2015). The analysis was performed on a residential building localized in Águas Claras/DF, which presents settlements measurements and loading tests. The work began with modeling the structure, using the CAD/TQS program, considering the rigid supports. With the results of the efforts, the effects on settlements were calculated using GARP software. It was then carried out a retrospective analysis of the structure requirements, with a flexibilization of support data recovered by GARP. This iteration was performed until the convergence of results of load and settlement was achieved. The effects of the ISE were verified for the first floors of the building. The largest variations were the normal stress $(\mathrm{Fz})$ of $0.7 \mathrm{kN}$ in P216 at the end of the 2nd floor; from the moment in $x(M x)$ of $-118.3 \mathrm{kN} . \mathrm{m}$ in P216 at the end of the 1st floor and from the moment in y (My) of -0.7 kN.m in P221 at the end of the 1st floor. In the settlements, the results were closer to the monitoring settlements after SSI. However, the average relative change is still high, reaching $-38.9 \%$. The results have shown to be satisfactory, as recent research indicates a similar decrease of settlement when considering the SSI, besides the increase in stresses.
\end{abstract}

Keywords: Soil-Structure interaction. Active efforts. Deep Foundations.

How to cite this article:

BAHIA, G. de A. D.; CUNHA, R. P. da; MOTA, N. M. B. Desempenho de edifícios altos com emprego da interação soloestrutura. PARC Pesquisa em Arquitetura e Construção, Campinas, SP, v. 12, p. e021005, 2021. DOI: http://dx.doi.org/10.20396/parc.v12i00.8658248 


\section{Introdução}

A partir do século XX, os avanços científicos na área e o estudo do comportamento dos materiais permitiram que as edificações modernas se tornassem cada vez mais altas, seja para atender às exigências do mercado, ora devido à limitação do espaço horizontal de construção ou à disputa de poder. Em consequência disso, o carregamento que chega à fundação, bem como a sua própria geometria tornaram-se maiores do que as consideradas no passado, enquanto a configuração das superestruturas tornou-se cada vez mais esbelta.

Dessa forma, o desafio do engenheiro, frente a essa perspectiva, é elaborar projetos seguros de forma mais econômica atendendo às exigências do mercado. Para que isso seja possível é necessária a utilização de técnicas que permitam uma boa aproximação do comportamento real da edificação.

O emprego de análises que consideram a interação entre as partes da edificação, superestrutura, infraestrutura (elemento estrutural de fundação) e terreno de fundação (maciço de solos), denominada interação solo-estrutura (ISE), apesar de complexa, exerce bastante influência na determinação da redistribuição de esforços tornando-se imprescindível para a verificação do desempenho global da edificação e dos sistemas estruturais.

\section{Fundamentação teórica}

As partes que compõem a edificação (superestrutura, subestrutura e o maciço de solo) não trabalham de forma autônoma, ou seja, existe uma relação de interdependência entre elas. Porém, na engenharia, de forma corriqueira, os projetos de estrutura e fundações são realizados separadamente, sem a consideração da interação soloestrutura, ou ainda com a consideração da ISE de forma negligente.

A consideração da ISE de forma negligenciada se deve principalmente:

- Aos engenheiros de estrutura analisarem o maciço como indeslocável, admitindo uma rigidez infinita ao solo. Porém, sabe-se que a rigidez da estrutura é muito maior que a rigidez do solo.

- Aos engenheiros de fundações admitirem os esforços aplicados apenas nos apoios, desprezando a sequência construtiva e a rigidez da estrutura.

- À análise da fundação, no cálculo estrutural, realizada por meio de um conjunto de molas, modelo proposto primeiramente por Winkler, que permite a consideração da deformação do solo, por meio de um coeficiente de rigidez de mola. Porém, esse coeficiente é obtido de forma aproximada, já que para o projeto de estruturas estão interessados apenas nas reações de apoio. Dessa forma, obtêm-se um resultado satisfatório para esses esforços, porém distante da realidade para os recalques das fundações.

Por esse motivo, a interação solo-estrutura tende a ser desprezada na elaboração dos projetos de edifícios, fazendo com que o projeto desenvolvido não demonstre o real comportamento da edificação. Porém, dependendo do grau de deformação do terreno e da rigidez da estrutura, a ISE pode modificar significativamente o comportamento do prédio (ARAÚJO; CARVALHO; DANZIGER, 2012).

\section{Histórico}

A seguir é apresentado um histórico da evolução do tema de interação solo-estrutura com o objetivo de compreender o que está sendo desenvolvido no estado da arte. 
Meyerhof (1953) apresentou um dos primeiros trabalhos nessa linha de pesquisa. O autor desenvolveu equações para a estimativa da rigidez de estruturas rígidas abertas ou fechadas com painéis de vedação, além de equações simplificadas que permitiam a substituição de uma edificação real por uma estrutura mais simples de rigidez equivalente. Neste trabalho o autor concluiu que a rigidez da infraestrutura é em geral bem menor que a rigidez da superestrutura.

Meyerhof (1953), ainda na mesma pesquisa, considerando em suas análises o efeito da interação solo-estrutura, observou que o solo, a infraestrutura e a superestrutura poderiam ser consideradas como uma unidade integral. $O$ autor observou que a rigidez estrutural não exerce grande influência sobre os recalques totais, porém os recalques diferenciais dependem do tipo e da rigidez da estrutura, além da variação da compressibilidade do solo e dos fatores que governam os recalques totais.

Posteriormente, Chamecki (1954) iniciou um processo iterativo por meio de uma sistemática de cálculo a partir das reações de apoio da estrutura considerada indeslocável e dos coeficientes de transferência de carga, provenientes de recalques unitários de cada apoio em separado. Em seguida, os apoios eram flexibilizados, sendo o processo repetido até que os valores das reações de apoio e recalques convergissem. Dessa forma, o autor observou que os recalques diferenciais passaram a ser menos acentuados, ajustando-se melhor aos resultados das medições em estruturas reais.

Poulos (1974) desenvolveu um cálculo matricial para a estimativa dos recalques de fundações superficiais considerando a ISE. Para a análise relacionou o comportamento da superestrutura com os recalques de apoio e o comportamento da fundação e do maciço de solos. Os resultados obtidos pelo estudo, em um pórtico plano, mostraram que, em geral, a rigidez da estrutura tende a reduzir os recalques diferenciais.

Aoki (1989) recomendou um modelo simples para o mecanismo de transferência de carga vertical isolada para o maciço de solos e, em 1997, o autor propôs o mesmo para o caso de grupo de estacas e de grupo de blocos integrados à superestrutura. Para o cálculo das estruturas considerando a ISE, sugeriu que se calculassem as cargas nos pilares considerando as fundações indeslocáveis. A partir dessas cargas era possível obter os recalques das fundações, para que em seguida, fossem flexibilizados os apoios com esses recalques e obtidos novos valores de cargas. O processo se repete até a convergência desejada.

Gusmão e Gusmão Filho (1990) estudaram um edifício residencial localizado em Recife no bairro de Boa Viagem. Dessa análise obtiveram como resultados os efeitos da ISE no desempenho das fundações, como a diminuição dos recalques diferenciais, redistribuição de cargas nos pilares e a influência do cintamento na rigidez global da estrutura.

Holanda Junior (1998) realizou um estudo considerando uma camada indeslocável no interior do maciço de solo e o processo construtivo em edifícios sob fundações diretas. O autor observou que a presença da camada indeslocável de solo se aproximava mais ao comportamento real do sistema, diminuindo os valores de recalques obtidos. Além disso, por meio de exemplos numéricos, destacou a importância de se considerar o processo construtivo da obra, pois a influência da rigidez da estrutura modificou significativamente os esforços obtidos.

Gusmão Filho (1998) observou que não somente nos pilares, mas também nas vigas, ocorre a redistribuição de esforços devido aos recalques das fundações, podendo até mesmo inverter os momentos na peça nos primeiros pavimentos. Dessa forma, o autor 
alerta para a importância de se considerar a transferência de cargas na edificação devido aos deslocamentos dos apoios, de forma a garantir a segurança da obra.

Iwamoto (2000) realizou um estudo em um edifício de múltiplos andares em fundação profunda, em que realizou uma modelagem tridimensional considerando a contribuição da rigidez transversal à flexão das lajes, a existência de excentricidade nas vigas em relação aos pilares e a hipótese de diafragma rígido no plano horizontal de cada pavimento. Com o estudo concluiu que a rigidez da estrutura contribui para a diminuição dos recalques diferenciais.

Jordão (2003) apresentou uma análise da interação solo-estrutura que consiste em um processo iterativo, em que, incialmente, determinam-se as reações da superestrutura considerando os apoios indeslocáveis. Posteriormente, por meio de um programa em linguagem FORTRAN, calculavam-se os deslocamentos e coeficientes de molas que substituiriam os apoios fixos da superestrutura para o cálculo das novas reações. Repete-se o processo até que as reações de duas interações consecutivas sejam aproximadamente iguais. Como resultados observou-se uma tendência na uniformização dos esforços horizontais e dos deslocamentos verticais e que a estabilidade global é influenciada pela interação solo-estrutura.

Gonçalves (2004) elaborou um estudo para observar a transferência de cargas nos pilares em um edifício localizado no Rio de Janeiro. Para isso realizou medidas de recalque e deformações na estrutura durante o processo de carregamento e, por meio do programa SAP 2000, comparou os esforços obtidos considerando a ISE com o modelo de apoios indeslocáveis.

Soares (2004) estudou a ISE na influência dos esforços da edificação e no recalque das fundações simulando diversas fases de carregamento. Para isso utilizou o Plaxis 3D e 2D para a modelagem das fundações e obtenção dos recalques e interagiu o programa com o CAD/TQS para a obtenção dos esforços. Como resultados comprovou a influência mais evidente da ISE nos primeiros pavimentos da edificação. Observando para a variação dos esforços com $25 \%$ da construção: 1 a $5 \%$ de redução na carga normal, 4 a $5 \%$ de aumento nos momentos em y e diminuição, e em alguns casos aumento, de 2 a $6 \%$ no momento em $z$.

Borges (2009) apresentou uma metodologia para avaliação do comportamento estrutural de edifícios altos em concreto armado baseado em indicadores que contemplam desde análises lineares até análises não lineares, tanto físicas, quanto geométricas, e análises dinâmicas. A metodologia foi realizada considerando diferentes condições de apoio: apoios indeslocáveis e apoios deslocáveis, considerando a ISE. Como resultados verificou-se a uniformização de recalques e redução das distorções angulares com a consideração da ISE, por outro lado, do ponto de vista estrutural, verificou-se a influência negativa evidenciada pelo aumento da sensibilidade aos efeitos de $2^{\mathrm{a}}$ ordem, pela redução da rigidez.

Araújo (2009) aplicou uma metodologia iterativa em duas edificações apoiadas sobre blocos de estacas de forma a obter a convergência dos recalques, obtidos por meio do desenvolvimento de um programa denominado AIEFE. Foram avaliados os efeitos da ISE nas reações de apoio, rigidezes e recalques dos pilares e como respostas observaram que existe uma maior distribuição de carga, recalques e rigidezes nos primeiros pavimentos. Foi observado também que o comportamento carga-recalque não linear das fundações exerceu bastante influência nos recalques, cargas e rigidezes dos pilares, ainda com a edificação em estágio avançado de construção, ou seja, com alta rigidez da estrutura. 
Antoniazzi (2011) realizou um estudo em um edifício comercial hipotético de oito pavimentos em estrutura de concreto armado considerando os efeitos da interação solo-estrutura. Foram calculados os recalques de fundações por meio de um programa, denominado ESPACIAL_ISE, desenvolvido em linguagem FORTRAN e interagido com o programa de cálculo estrutural TQS. Como resultados comprovou que a deformação do solo nos projetos estruturais gera uma redistribuição de esforços na estrutura, e essas deformações podem ocasionar mudanças significativas no dimensionamento das peças. Além disso, observou a influência da sequência construtiva no dimensionamento estrutural e a suavização da deformada de recalques ao considerar o modelo integrado.

Morosini, Navia e Cunha (2014) fizeram uma análise comparativa, com e sem ISE, para uma edificação de 4 pavimentos com fundação profunda. As modelagens foram realizadas utilizando o módulo SISE do software TQS. Após as análises foi constatado que as maiores diferenças de carga ocorreram nos pavimentos mais próximos das fundações, sendo registrado um aumento de carga com a ISE. Quanto aos recalques observou-se uma conformação na sua deformada, sendo observada uma variação irrelevante dos valores, com magnitudes de $0,1 \mathrm{~mm}$.

Ritter et al. (2020) avaliaram a influência da ISE nas cargas, recalques e custo de materiais de uma edificação de pequeno porte com fundações profundas. Para isso realizaram oito estudos de caso, considerando a edificação com 4, 6 e 8 pavimentos e com 3 perfis de solo diferentes. Após as análises observaram que as cargas e os recalques não apresentaram variações significativas e dentro os itens avaliados, o custo dos materiais foi o que obteve menos variação.

Fatores influentes no mecanismo da interação solo-estrutura

O mecanismo da interação solo-estrutura está associado a uma série de variáveis, como a rigidez da estrutura, o processo de carregamento, as características do solo, a geometria em planta da edificação, a influência de edificações vizinhas, a deformada de recalques da edificação, entre outros.

\section{Rigidez da estrutura}

O aumento da rigidez está associado ao aumento no número de pavimentos do edifício. Segundo Meyerhof (1953), conforme o progresso de construção e carregamento da obra, a rigidez tende a aumentar até uma rigidez limite, sendo mais importante considerar a rigidez da superestrutura, uma vez que a rigidez da infraestrutura é praticamente desprezível em relação à primeira.

De acordo com Goshy (1978) a maior influência da rigidez da estrutura ocorre nos primeiros pavimentos e, uma vez atingido o seu limite, o acréscimo do número de pavimentos não influencia mais na redistribuição de carga nos apoios, sendo esta influenciada apenas pelo carregamento.

Deformada de recalques

Um efeito importante da ISE foi relatado em um dos trabalhos de Moura (1995), o qual relatou que existe uma tendência de uniformização de recalques com o aumento da rigidez da edificação, bem como, uma diminuição de recalques diferenciais e de momentos fletores nas vigas e pilares.

Os recalques tendem a se uniformizar devido à amarração dos elementos estruturais, que permite a transferência de carga dos pilares que sofreram maiores deslocamentos, e por essa razão não conseguiram absorver toda a carga que estava destinada a eles, para os pilares vizinhos. Esse mecanismo não exerce grande 
influência nos recalques absolutos, mas resulta na redução dos recalques diferenciais que são os maiores responsáveis por eventuais danos nas edificações.

\section{Formato da planta baixa da edificação}

Estudos desenvolvidos por Barata (1986) e Gusmão (1990) mostraram que a forma, em planta, da edificação também influencia na uniformização de recalques. Foram feitas análises, com resultados de medições de recalques, em diversos tipos de edifícios e observou-se essa tendência à uniformização de recalques. Quanto mais próximo de um quadrado fosse a planta da edificação, maior era essa tendência. Gusmão (1990) observou que esse efeito era mais acentuado em estruturas flexíveis.

\section{GARP}

O programa GARP foi desenvolvido por Poulos em 1994 e posteriormente modificado por Poulos e Small em 1998 e a partir de então sofreu algumas atualizações ao longo dos anos gerando novas versões (CAMPOS, 2011).

O programa é uma ferramenta numérica de fácil utilização e permite a análise de radiers de diversos formatos, submetidos a cargas concentradas e momentos fletores.

Neste programa o radier é representado como elementos planos de placa e é analisado pelo MEF, enquanto as estacas são substituídas por molas, modelo de Winkler, considerando a interação entre os elementos próximos (SALES, 2000).

A interação das estacas entre si e com o radier se dá através de fatores de interação.

De acordo com Sales (2000) este programa permite incorporar:

- Estratificação do solo;

- Limite de capacidade de carga na compressão e na tração;

- Estacas com diferentes propriedades dentro do sistema de fundação;

- Possibilidade de aplicação de carregamentos distribuídos, concentrados (verticais) e momentos em duas direções;

- Rigidez do bloco.

O programa ainda permite realizar a análise considerando o radier em contato com o solo ou não (CORDEIRO, 2007). Porém, o programa traz algumas limitações, tais como: a necessidade de outro programa para o cálculo da rigidez relativa das estacas e dos fatores de interação e não considera os carregamentos horizontais.

\section{Caracterização do empreendimento}

O edifício residencial em questão situa-se em Águas Claras - DF e compreende duas Torres A e B e periferias. A obra foi iniciada no $2^{\circ}$ semestre de 2010 e foi concluída no $2^{\circ}$ semestre de 2014. Cada Torre possui um total de vinte e dois pavimentos, sendo: dois subsolos, um térreo e dezenove pavimentos tipo, conforme Figura 1.

Em específico, as análises realizadas nesta pesquisa se referem a Torre $B$ do empreendimento. A estrutura da edificação foi realizada em concreto armado com alvenaria em bloco de concreto vazado e revestimento cerâmico. As fundações da Torre foram realizadas em estaca hélice monitoradas, com diâmetro variando de $400 \mathrm{e}$ $500 \mathrm{~mm}$, e bloco de coroamento. Foi realizada uma prova de carga com estaca de 500 $\mathrm{mm}$ e $13 \mathrm{~m}$ de comprimento, não pertencente à obra, sendo o recalque obtido para sua carga de trabalho $(843,7 \mathrm{kN})$ de $3,8 \mathrm{~mm}$. A configuração dos blocos e a localização da prova de carga estática realizada se apresentam na Figura 2. 
BAHIA, G. de A. D.; CUNHA, R. P. da; MOTA, N. M. B.

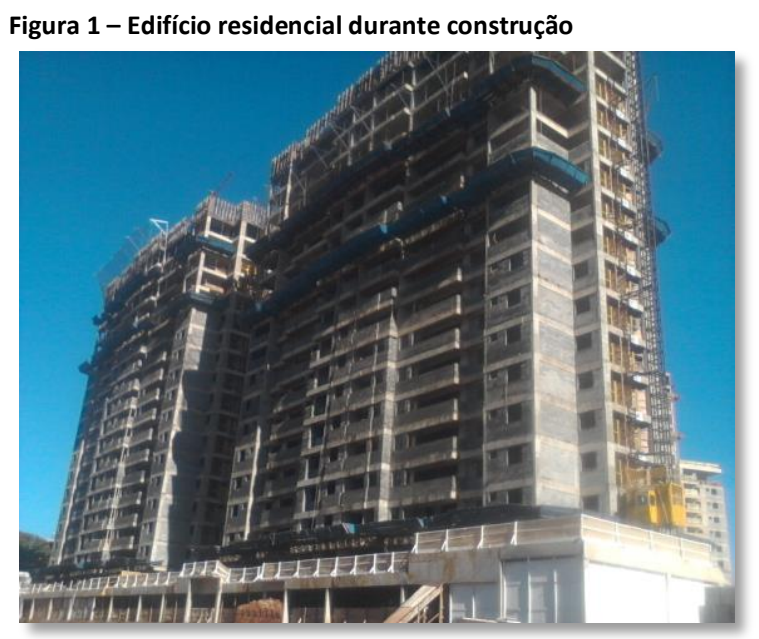

Fonte: Bahia (2015)

Na região central da Torre apresentam-se dois radiers estaqueados, com dimensões 5,6 m x 8,6 m x 1,4 m, que recebem cinco pilares e são compostos por 33 (trinta e três) estacas cada. $O$ grupo de estacas pertencentes aos radiers possuem aproximadamente $10 \mathrm{~m}$ de comprimento, sendo a altura do poço do elevador de 1,6 m e do bloco de coroamento de $1,4 \mathrm{~m}$, resultando num comprimento útil de $7 \mathrm{~m}$. As demais estacas da obra apresentaram comprimento médio de $15 \mathrm{~m}$.

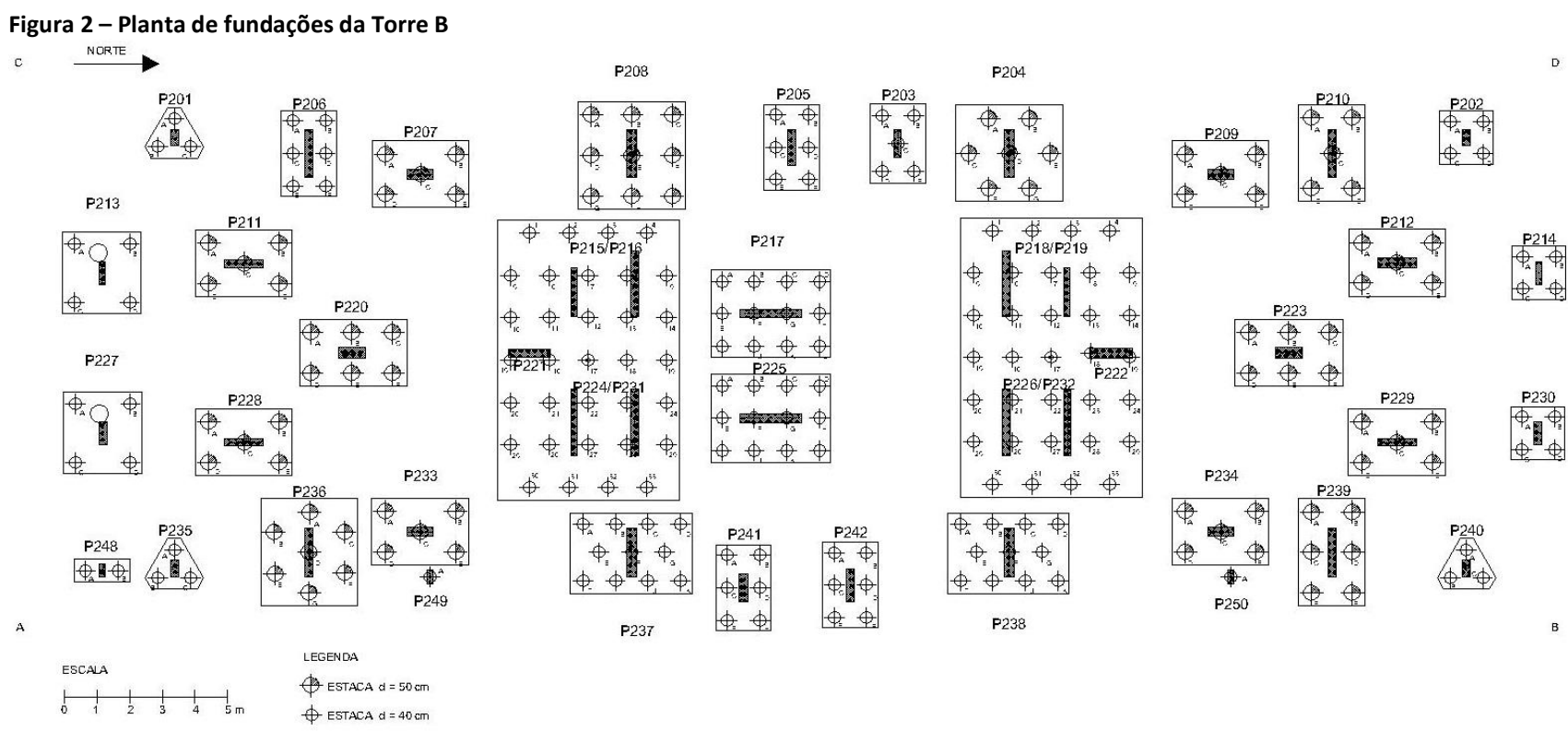

Fonte: Bahia (2015).

Foram realizados seis furos de sondagem à percussão e dois furos de sondagem mista (percussão e trado), conforme locação apresentada na Figura 3. O perfil do solo foi obtido por meio do programa RockWorks v.16, para melhor visualização dos estratos de solo (Figura 4). Observou-se que na região da Torre B existem apenas duas camadas de solo, sendo o silte arenoso variegado seguido de silte arenoso roxo. $\mathrm{O}$ nível d'água foi encontrado no furo SP06 na profundidade de 2,1 m e no furo SP05 na profundidade de 2,9 $\mathrm{m}$. 
BAHIA, G. de A. D.; CUNHA, R. P. da; MOTA, N. M. B.

Desempenho de edifícios altos com emprego da interação solo-estrutura

Figura 3 - Locação das sondagens

C

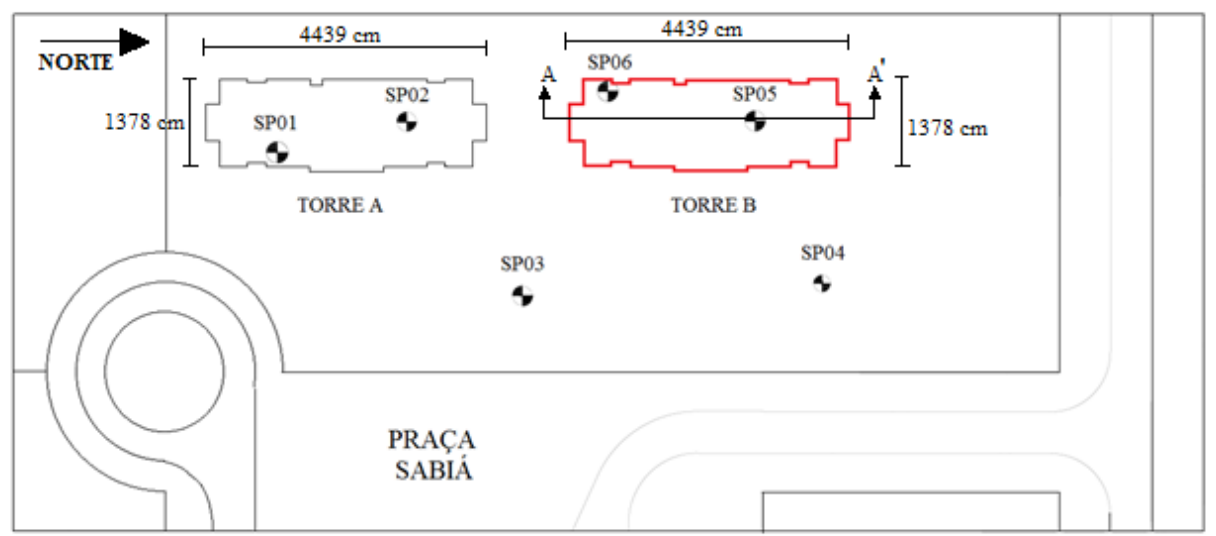

A

B

Fonte: Bahia (2015).

Figura 4 - Perfil de solo 3D com os furos de sondagem SPT: a) Perfil do solo completo, b) Perfil do solo sem a primeira camada, c) Perfil do solo sem a 1a e 2a camadas e d) Perfil do solo sem a 1a, 2aㅡ e 3a camadas

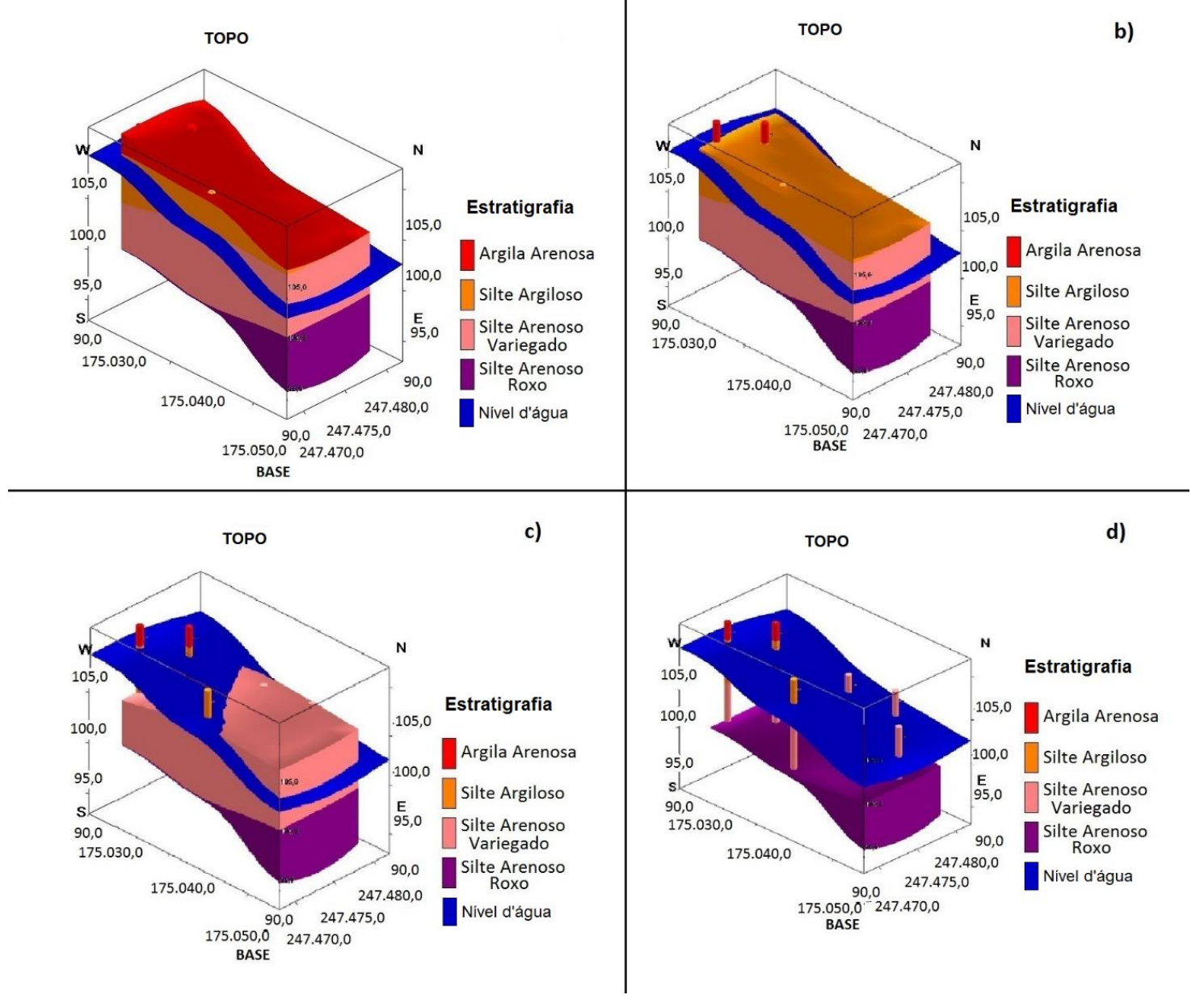

Fonte: Bahia (2015).

\section{Metodologia}

Para a realização das análises foram disponibilizadas pela construtora do empreendimento as plantas de arquitetura, estrutura e fundações. Com base nos referidos projetos modelou-se a estrutura no programa CAD/TQS, de forma que os 
esforços obtidos pela modelagem do pórtico espacial fossem similares aos esforços apresentados no projeto estrutural do empreendimento.

A modelagem do edifício (modelo tridimensional e análise não-linear geométrica) no CAD/TQS, foi realizada, inicialmente, considerando os apoios indeslocáveis para a obtenção dos esforços internos da estrutura.

Em seguida, com os dados de saída da estrutura, obtidos anteriormente, procedeu-se a análise para obtenção dos recalques nas fundações, utilizando-se o GARP. Para a calibração dos parâmetros de entrada do programa GARP utilizou-se o programa DEFPIG na obtenção dos fatores de interação entre as fundações (a) e dos coeficientes de rigidez das estacas (K). A partir dos resultados de deslocamento obtidos pelo GARP, foram calculados os coeficientes de mola $\left(\mathrm{k}_{\mathrm{i}}\right)$, utilizando a carga obtida pelo CAD/TQS e o recalque obtido pelo GARP.

Após esse procedimento, realizou-se uma nova análise de esforços internos na estrutura utilizando o software CAD/TQS, porém flexibilizando os apoios por meio do valor do coeficiente de mola $\left(\mathrm{k}_{\mathrm{i}}\right)$ calculado. Com os novos esforços realizou-se a análise de recalque no GARP, junto ao software CAD/TQS, com o objetivo de atingir a convergência dos resultados de carga e recalque.

\section{Análises do DEFPIG}

A Tabela 1 apresenta os dados de entrada utilizados no programa DEFPIG para obtenção dos fatores de interação e dos coeficientes de rigidez das estacas.

\begin{tabular}{ccccc}
\hline Tabela 1 - Dados de entrada do DEFPIG & & \\
\hline Diâmetro $(\mathrm{cm})$ & $\begin{array}{c}\text { Comprimento } \\
\text { total }(\mathrm{m})\end{array}$ & $\begin{array}{c}\text { Módulo de Young } \\
\text { da estaca }\left(\mathrm{kN} / \mathrm{m}^{2}\right)\end{array}$ & $\begin{array}{c}\text { Momento de inércia } \\
\text { na direção } \times\left(\mathrm{m}^{4}\right)\end{array}$ & $\begin{array}{c}\text { Razão entre área da } \\
\text { estaca na seção } \mathrm{x}\end{array}$ \\
\hline 40 & 10 & $2.10^{7}$ & 0,00125 & 1 \\
\hline 40 & 15 & $2.10^{7^{\prime}}$ & 0,00125 & 1 \\
\hline 50 & 15 & $2.10^{7}$ & 0,00306 & 1 \\
\hline
\end{tabular}

Fonte: Bahia (2015)

Para a análise das estacas, o solo foi dividido em elementos de 1 metro de espessura.

Para a obtenção dos módulos de Young de cada camada de solo, utilizou-se o SP05, por ser a mais representativa, e fez-se uma aproximação utilizando uma correlação com o valor do NSPT (sugerida por Poulos, 1998), conforme apresentado na Tabela 2.

\begin{tabular}{cc}
\multicolumn{3}{c}{ Tabela 2 - Módulo de Young do solo com cor } \\
\hline $\mathrm{N}_{\mathrm{SPT}}$ & $\mathrm{E}_{\mathrm{Sv}}$ ( $\left.\mathrm{MPa}\right)$ \\
\hline 7 & 21 \\
\hline 15 & 45 \\
\hline 24 & 72 \\
\hline 29 & 87 \\
\hline 33 & 99 \\
\hline 41 & 123 \\
\hline 46 & 138 \\
\hline 50 & 150 \\
\hline 52 & 156 \\
\hline 53 & 159 \\
\hline 53 & 159 \\
\hline 53 & 159 \\
\hline 53 & 159 \\
\hline 53 & 159 \\
\hline 53 & 159 \\
\hline
\end{tabular}

Fonte: Bahia (2015). 
BAHIA, G. de A. D.; CUNHA, R. P. da; MOTA, N. M. B.

Desempenho de edifícios altos com emprego da interação solo-estrutura

O coeficiente de Poisson do solo utilizado para a análise foi de 0,3 e os espaçamentos relativos (s/d) foram limitados, conforme Tabela 3.

\begin{tabular}{cc} 
Tabela 3 - Espaçamento relativo $(s / d)$ & \\
\hline Fator de interação $(\alpha)$ & $\mathrm{s} / \mathrm{d}$ \\
\hline $\boldsymbol{\alpha}_{1}$ & 1,5 \\
\hline $\boldsymbol{\alpha}_{2}$ & 2 \\
\hline $\boldsymbol{\alpha}_{3}$ & 2,5 \\
\hline $\boldsymbol{\alpha}_{4}$ & 3 \\
\hline $\boldsymbol{\alpha}_{5}$ & 4 \\
\hline $\boldsymbol{\alpha}_{6}$ & 5 \\
\hline $\boldsymbol{\alpha}_{7}$ & 6 \\
\hline $\boldsymbol{\alpha}_{8}$ & 7 \\
\hline $\boldsymbol{\alpha}_{9}$ & 8 \\
\hline
\end{tabular}

Fonte: Bahia (2015).

\section{Análises GARP e CAD/TQS}

A análise foi realizada com a utilização da combinação de carregamento de peso próprio e carga permanente $(\mathrm{PP}+\mathrm{G})$, considerando as fases construtivas do nivelamento e da última medição de recalques, a não linearidade do modelo, as cargas verticais fornecidas pelo CAD/TQS para utilização no GARP e a simplificação da flexibilização de apoios com a utilização, apenas, do coeficiente de mola à translação em z.

O programa GARP foi calibrado com os fatores de interação e rigidez relativa da estaca obtidos por meio do software DEFPIG, utilizando para tal a correlação para obtenção do módulo de Young do solo de 3 x NSPT e a limitação de espaçamento relativo de 8 .

Após a obtenção dos deslocamentos dos blocos no GARP procedeu-se a flexibilização dos apoios no CAD/TQD, por meio do coeficiente de mola à translação em z. O procedimento foi repetido até a convergência das reações de apoio com os valores de recalque.

O delineamento da metodologia utilizada está apresentado na Figura 5.

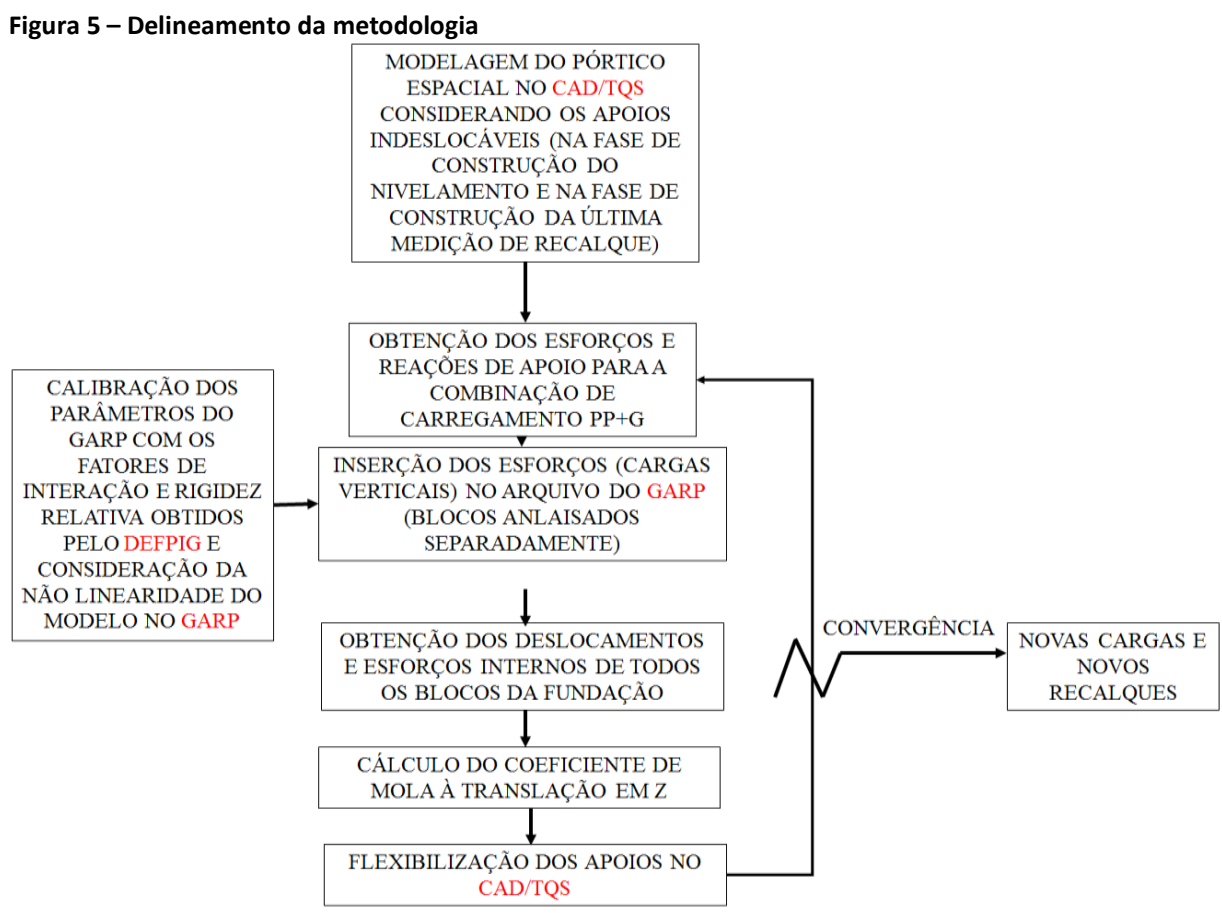

Fonte: Bahia (2015). 
BAHIA, G. de A. D.; CUNHA, R. P. da; MOTA, N. M. B.

Desempenho de edifícios altos com emprego da interação solo-estrutura

\section{Resultados e discussões}

\section{DEFPIG}

Neste item são apresentadas as análises realizadas no programa DEFPIG para as diferentes configurações de estacas. As Tabelas 4, 5 e 6 apresentam os resultados de fatores de iteração e rigidez da estaca obtidos para cada configuração de estaca analisada.

\begin{tabular}{|c|c|c|c|c|c|}
\hline \multicolumn{6}{|c|}{ ESTACAS HÉLICE COM $\phi=40 \mathrm{~cm}$ E H $=10 \mathrm{~m}$} \\
\hline \multicolumn{4}{|c|}{ Dados de entrada } & \multicolumn{2}{|c|}{ Dados de saída } \\
\hline Propriedade & Valor & Unid. & $\begin{array}{l}\text { Espaçamento } \\
\text { relativo }(\mathrm{s} / \mathrm{d})\end{array}$ & $\begin{array}{l}\text { Fatores de } \\
\text { interação }\end{array}$ & $\begin{array}{c}\text { Rigidez da } \\
\text { estaca }(\mathrm{kN} / \mathrm{m})\end{array}$ \\
\hline Comprimento & 10 & $\mathrm{~m}$ & 1,5 & 0,361 & \multirow{10}{*}{381727} \\
\hline $\begin{array}{c}\text { Diâmetro do eixo da } \\
\text { estaca }\end{array}$ & 0,40 & $\mathrm{~m}$ & 2 & 0,278 & \\
\hline \multirow{2}{*}{$\begin{array}{l}\text { Diâmetro da } \\
\text { extremidade da estaca }\end{array}$} & \multirow{2}{*}{0,40} & \multirow{2}{*}{$\mathrm{m}$} & 2,5 & 0,251 & \\
\hline & & & 3 & 0,228 & \\
\hline \multirow{2}{*}{$\begin{array}{l}\text { Módulo de Young do } \\
\text { material da estaca } \\
\text { (concreto) }\end{array}$} & \multirow[b]{2}{*}{$2.10^{7}$} & \multirow[b]{2}{*}{$\mathrm{kN} / \mathrm{m}^{2}$} & 4 & 0,193 & \\
\hline & & & 5 & 0,166 & \\
\hline \multirow{2}{*}{$\begin{array}{l}\text { Momento de inércia na } \\
\text { seção } x\end{array}$} & \multirow{2}{*}{0,001256} & \multirow{2}{*}{$\mathrm{m}^{4}$} & 6 & 0,144 & \\
\hline & & & 7 & 0,127 & \\
\hline $\begin{array}{c}\text { Coeficiente de Poisson } \\
\text { do solo }\end{array}$ & 0,3 & - & 8 & 0,111 & \\
\hline $\begin{array}{l}\text { Módulo de Young do } \\
\text { material subjacente a } \\
\text { camada de solo } \\
\text { impenetrável }\end{array}$ & $2.10^{7}$ & $\mathrm{kN} / \mathrm{m}^{2}$ & & & \\
\hline
\end{tabular}

Fonte: Bahia (2015).

Tabela 5 - Fatores de interação e rigidez da estaca para estacas com $\Phi=40 \mathrm{~cm}$ e $\mathbf{H}=\mathbf{1 5} \mathrm{m}$

\begin{tabular}{|c|c|c|c|c|c|}
\hline \multicolumn{6}{|c|}{ ESTACAS HÉLICE COM $\phi=40 \mathrm{~cm}$ E H = $15 \mathrm{~m}$} \\
\hline \multicolumn{4}{|c|}{ Dados de entrada } & \multicolumn{2}{|c|}{ Dados de saída } \\
\hline Propriedade & Valor & Unid. & $\begin{array}{l}\text { Espaçamento } \\
\text { relativo (s/d) }\end{array}$ & $\begin{array}{l}\text { Fatores de } \\
\text { interação }\end{array}$ & $\begin{array}{c}\text { Rigidez da } \\
\text { estaca } \\
\text { (kN/m) }\end{array}$ \\
\hline Comprimento & 15 & $\mathrm{~m}$ & 1,5 & 0,260 & \multirow{10}{*}{436441} \\
\hline Diâmetro do eixo da estaca & 0,40 & $\mathrm{~m}$ & 2 & 0,217 & \\
\hline \multirow{2}{*}{$\begin{array}{l}\text { Diâmetro da extremidade da } \\
\text { estaca }\end{array}$} & \multirow{2}{*}{0,40} & \multirow{2}{*}{$\mathrm{m}$} & 2,5 & 0,202 & \\
\hline & & & 3 & 0,189 & \\
\hline \multirow{2}{*}{$\begin{array}{c}\text { Módulo de Young do } \\
\text { material da estaca } \\
\text { (concreto) }\end{array}$} & \multirow[b]{2}{*}{$2.10^{7}$} & \multirow[b]{2}{*}{$\mathrm{kN} / \mathrm{m}^{2}$} & 4 & 0,168 & \\
\hline & & & 5 & 0,151 & \\
\hline \multirow{2}{*}{$\begin{array}{l}\text { Momento de inércia na } \\
\text { seção } x\end{array}$} & \multirow{2}{*}{0,001256} & \multirow{2}{*}{$\mathrm{m}^{4}$} & 6 & 0,136 & \\
\hline & & & 7 & 0,124 & \\
\hline $\begin{array}{l}\text { Coeficiente de Poisson do } \\
\text { solo }\end{array}$ & 0,3 & - & 8 & 0,113 & \\
\hline $\begin{array}{l}\text { Módulo de Young do } \\
\text { material subjacente a } \\
\text { camada de solo } \\
\text { impenetrável }\end{array}$ & $2.10^{7}$ & $\mathrm{kN} / \mathrm{m}^{2}$ & & & \\
\hline
\end{tabular}


BAHIA, G. de A. D.; CUNHA, R. P. da; MOTA, N. M. B.

Desempenho de edifícios altos com emprego da interação solo-estrutura

\begin{tabular}{|c|c|c|c|c|c|}
\hline \multicolumn{6}{|c|}{ ESTACAS HÉLICE COM $\phi=50 \mathrm{~cm} \mathrm{E} \mathrm{H=15} \mathrm{m}$} \\
\hline \multicolumn{4}{|c|}{ Dados de entrada } & \multicolumn{2}{|c|}{ Dados de saída } \\
\hline Propriedade & Valor & Unid. & $\begin{array}{l}\text { Espaçamento } \\
\text { relativo (s/d) }\end{array}$ & $\begin{array}{c}\text { Fatores } \\
\text { de } \\
\text { interação }\end{array}$ & $\begin{array}{c}\text { Rigidez da } \\
\text { estaca }(k N / m)\end{array}$ \\
\hline Comprimento & 15 & $\mathrm{~m}$ & 1,5 & 0,269 & \multirow{10}{*}{546836} \\
\hline Diâmetro do eixo da estaca & 0,50 & $\mathrm{~m}$ & 2 & 0,216 & \\
\hline \multirow{2}{*}{$\begin{array}{l}\text { Diâmetro da extremidade } \\
\text { da estaca }\end{array}$} & \multirow{2}{*}{0,50} & \multirow{2}{*}{$\mathrm{m}$} & 2,5 & 0,197 & \\
\hline & & & 3 & 0,181 & \\
\hline \multirow{2}{*}{$\begin{array}{l}\text { Módulo de Young do } \\
\text { material da estaca } \\
\text { (concreto) }\end{array}$} & \multirow[b]{2}{*}{$2.10^{7}$} & \multirow[b]{2}{*}{$\mathrm{kN} / \mathrm{m}^{2}$} & 4 & 0,156 & \\
\hline & & & 5 & 0,137 & \\
\hline \multirow{2}{*}{$\begin{array}{l}\text { Momento de inércia na } \\
\text { seção } x\end{array}$} & \multirow{2}{*}{0,003066} & \multirow{2}{*}{$m^{4}$} & 6 & 0,120 & \\
\hline & & & 7 & 0,107 & \\
\hline $\begin{array}{l}\text { Coeficiente de Poisson do } \\
\text { solo }\end{array}$ & 0,3 & - & 8 & 0,095 & \\
\hline $\begin{array}{l}\text { Módulo de Young do } \\
\text { material subjacente a } \\
\text { camada de solo } \\
\text { impenetrável }\end{array}$ & $2.10^{7}$ & $\mathrm{kN} / \mathrm{m}^{2}$ & & & \\
\hline
\end{tabular}

A Figura 6 apresenta os resultados da relação entre o espaçamento relativo (s/d) e dos fatores de interação ( $\alpha$ ), das Tabelas 4,5 e 6 . Observa-se que na medida que o espaçamento relativo entre as estacas aumenta os fatores de interação das estacas diminuem, conforme o esperado.

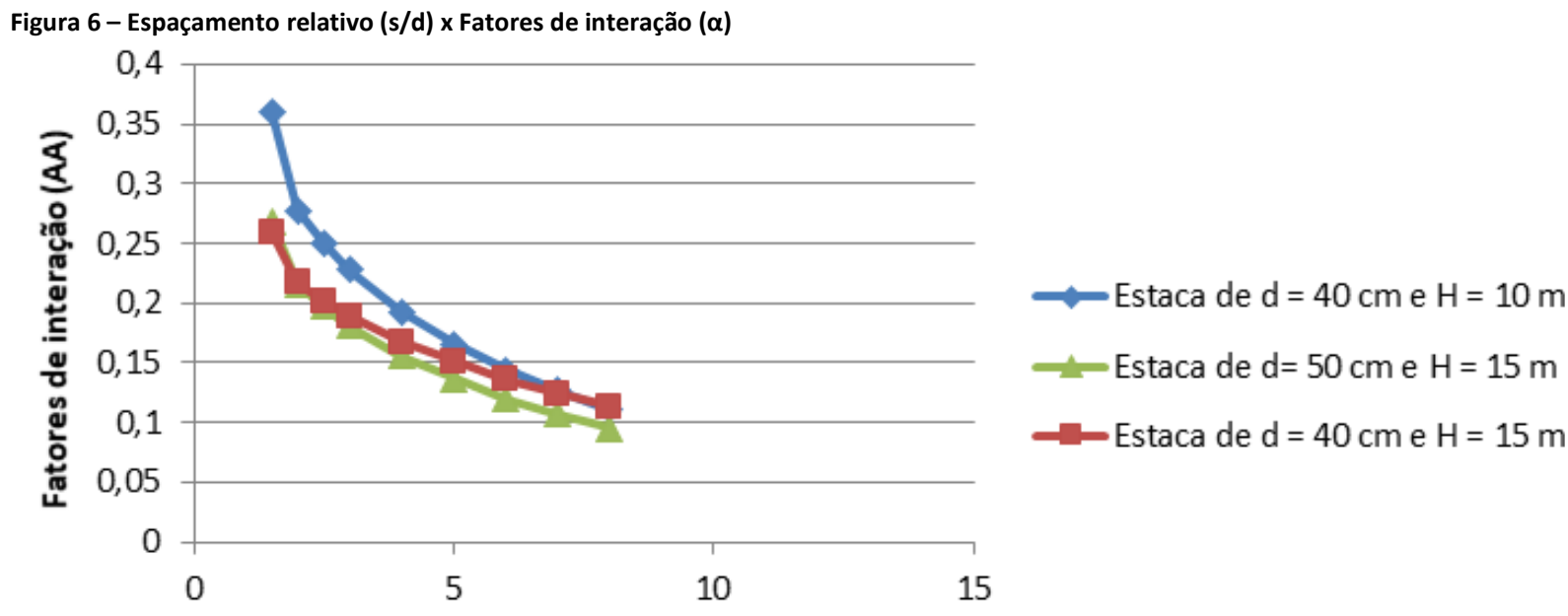

Espaçamento relativo (s/d)

Fonte: Bahia (2015).

A Figura 7 apresenta a curva carga $x$ recalque (em escala logarítmica) obtida por meio de prova de carga junto às curvas de carga e recalque simuladas no GARP, para cada configuração de estaca analisada no DEFPIG. Esta Figura tem o intuito de verificar se os cálculos realizados pelo DEFPIG para os fatores de interação se ajustam bem à curva carga $x$ recalque. 
BAHIA, G. de A. D.; CUNHA, R. P. da; MOTA, N. M. B.

Desempenho de edifícios altos com emprego da interação solo-estrutura

Figura 7 - Curva carga recalque junto aos resultados obtidos pelo GARP

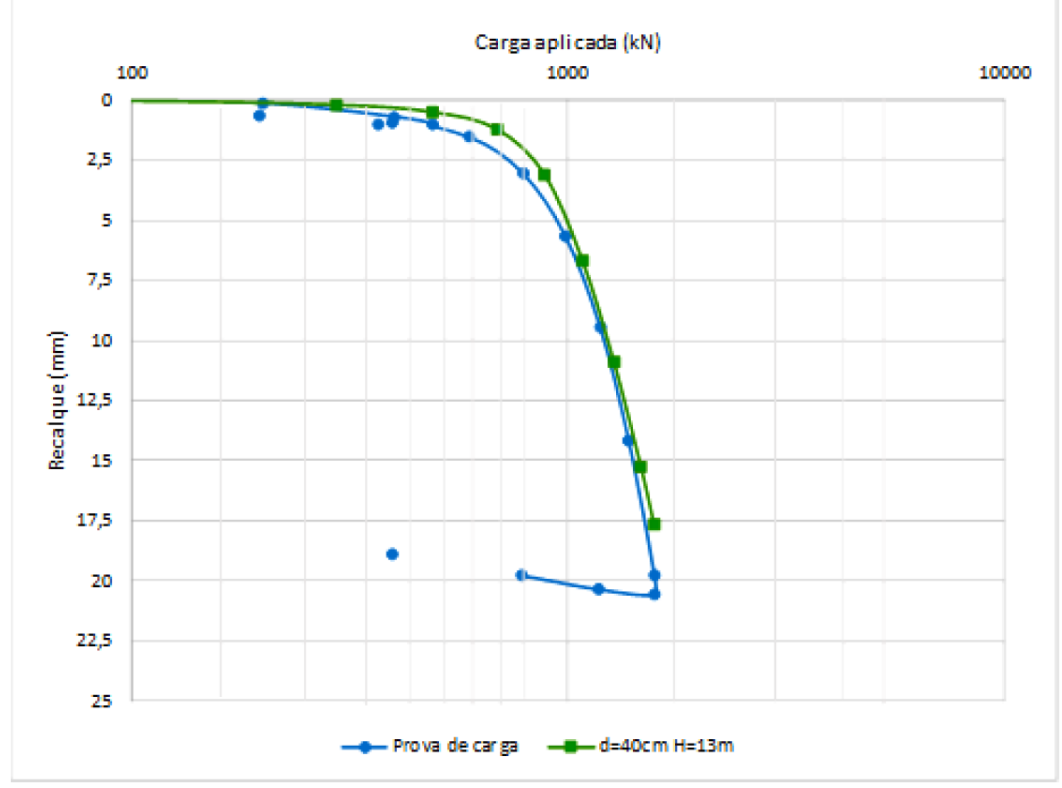

Fonte: Bahia (2015).

Na Figura 7, o trecho linear inicial e o não linear foram contemplados na retroanálise. As curvas simuladas no GARP para a estaca da prova de carga se ajustaram bem à curva carga $\mathrm{x}$ recalque.

\section{GARP e CAD/TQS}

Para obtenção da convergência dos resultados de carga e recalque foram realizadas 3 (três) iterações entre os programas GARP e CAD/TQS. Destaca-se que foi utilizado um valor específico de $\mathrm{k}$ para cada apoio da edificação, e como hipótese simplificadora, levou-se em consideração apenas o valor vertical à translação em z de k. Não foram considerados os momentos fornecidos pelo CAD/TQS no programa GARP, uma vez que só foi considerado o $\mathrm{k}$ à translação vertical em $\mathrm{z}$.

Vale ressaltar, que nessa análise todos os blocos foram calculados separadamente no GARP, com a consideração da não linearidade, considerando o recalque conforme a fase construtiva em que foi feita a medição de recalque (desconsiderados os recalques da fase de nivelamento da obra).

A Figura 8 apresenta a média do valor de $\mathrm{k}$ para todos os pilares para a iteração realizada para a fase construtiva em que foi realizada a última medição de recalque. Observa-se na Figura 8 que a média de k, estabiliza na $3^{\mathrm{a}}$ iteração, sendo 1172187 kN/m.

Figura 8 - Média de $k$ à translação vertical em z para edificação com 25 andares

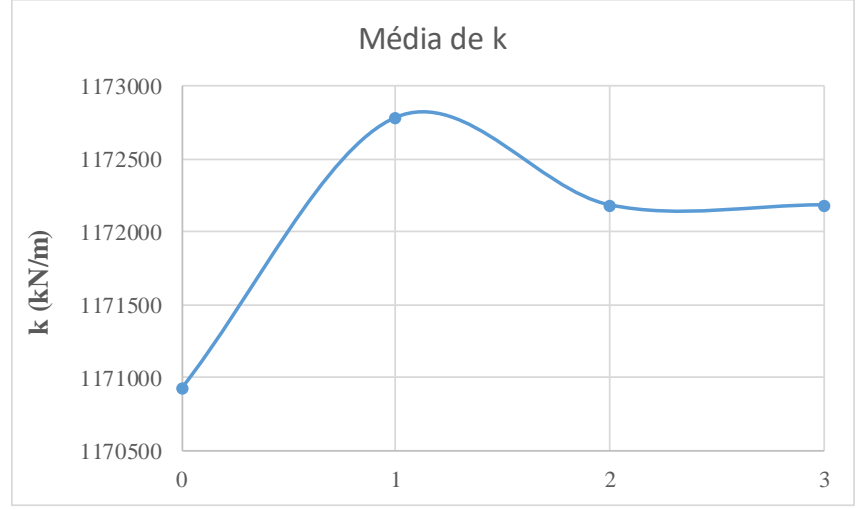

Fonte: Bahia (2015). 
A seguir serão apresentados apenas os valores das análises para a edificação na fase da última medição de recalque.

A Figura 9 apresenta a variação das cargas verticais nos pilares nas situações com e sem ISE. Observa-se que a carga vertical não variou de forma significativa para nenhum pilar, sendo a média da variação relativa de 1,91\%.

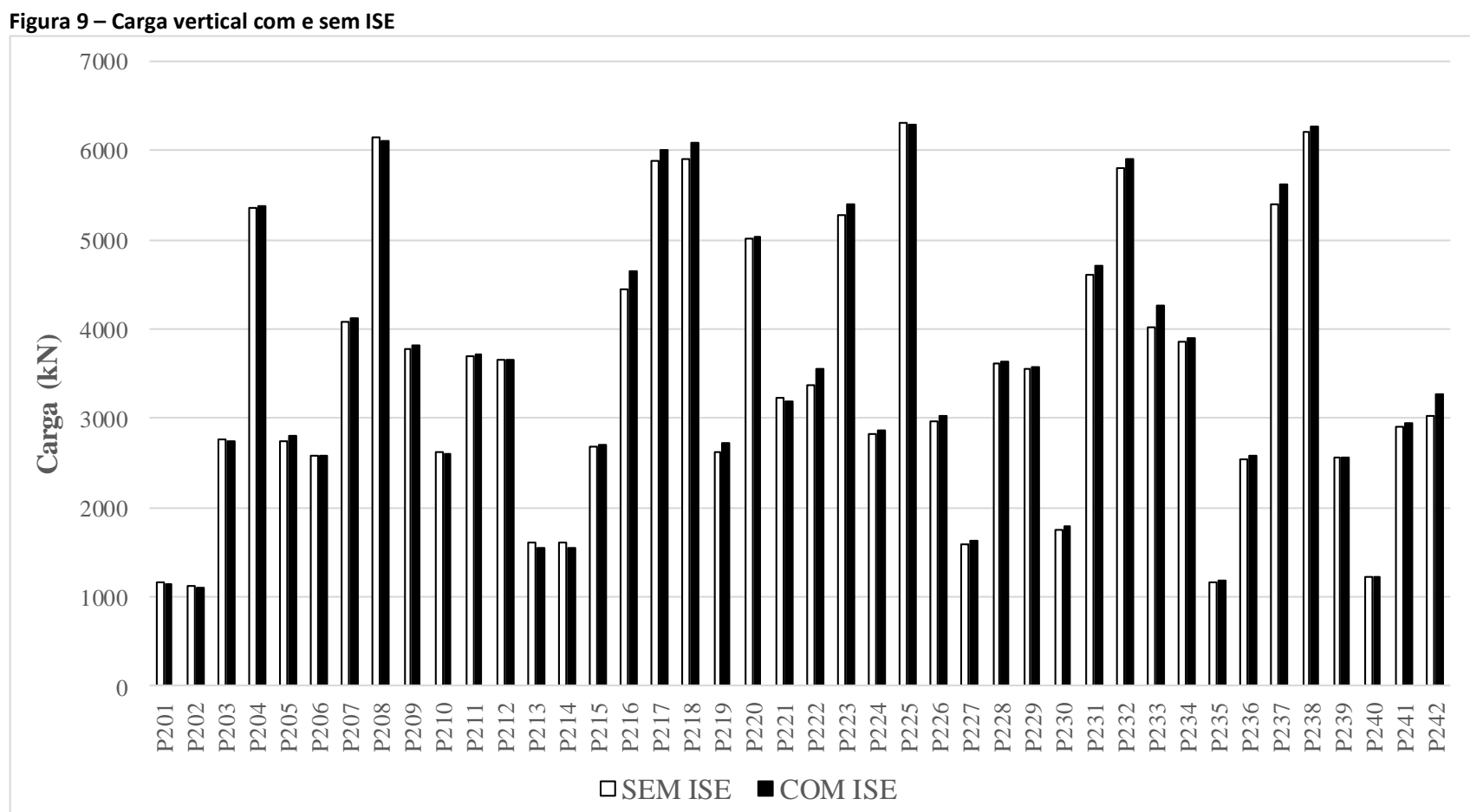

Fonte: Bahia (2015).

As Figuras 10 a 12 apresentam os esforços ( $\mathrm{Fz}$ - Força cortante, $\mathrm{Mx}$ - Momento fletor em $\mathrm{x}$ e My - Momento fletor em y) nos pilares obtidos antes e após a consideração da interação solo-estrutura.

Na Figura 10 verifica-se pouca variação do esforço normal para os pilares da edificação antes e após a ISE. Sendo a variação mais evidenciada nos primeiros pavimentos, correspondente a $0,7 \mathrm{kN}$ para o $\mathrm{P} 216$ ao final do $2^{\circ}$ pavimento. Destaca-se que a carga normal ora reduziu ora aumentou, não havendo uma tendência clara.

Na Figura 11 tem-se que a consideração da ISE gerou um aumento de momento na direção $x$, nos primeiros pavimentos, chegando a atingir até o limite do $5^{\circ}$ pavimento. Notou-se também, que em alguns pavimentos esse momento chega a inverter o sentido, mudando de positivo para negativo ou vice-versa, sendo a maior variação de 118,3 kN.m para o P216 ao final do $1^{\circ}$ pavimento.

$\mathrm{Na}$ Figura 12 observou-se uma diferença no momento $M_{y}$ considerando o cálculo convencional e a ISE, nos primeiros pavimentos (até o $5^{\circ}$ pavimento), porém a magnitude da variação observada é, no geral, menor que para o momento em x. A maior variação de $M_{\mathrm{y}}$ apontada (considerando as análises com ISE e SEM ISE) foi de $0,7 \mathrm{kN} . \mathrm{m}$ para o $\mathrm{P} 221$ ao final do $1^{\circ}$ pavimento. 
BAHIA, G. de A. D.; CUNHA, R. P. da; MOTA, N. M. B.

Desempenho de edifícios altos com emprego da interação solo-estrutura

Figura 10 - Variação do esforço normal antes e após a ISE para os pilares a) P215 b) P216 c) P221 d) P224 e) P231

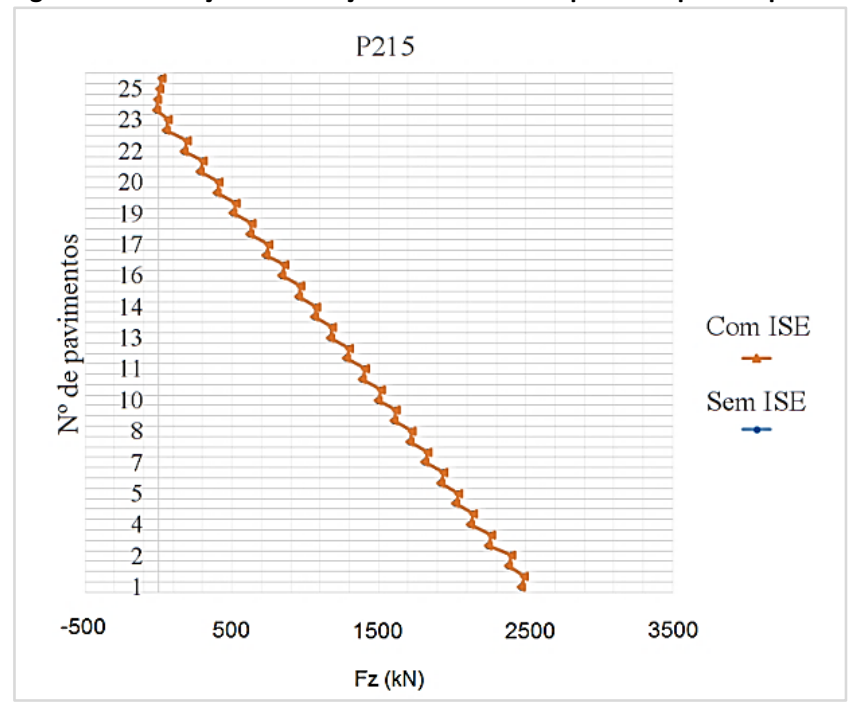

(a)

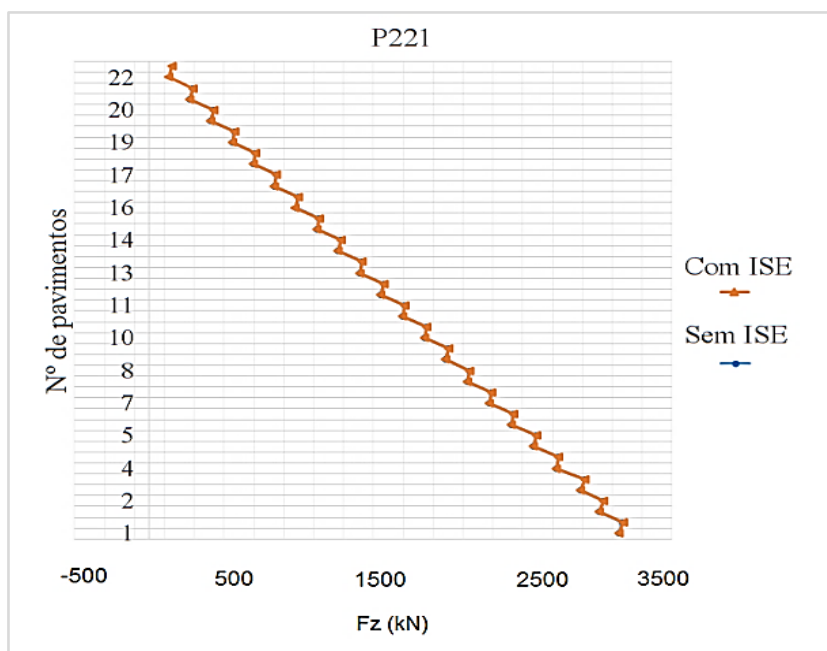

(c)

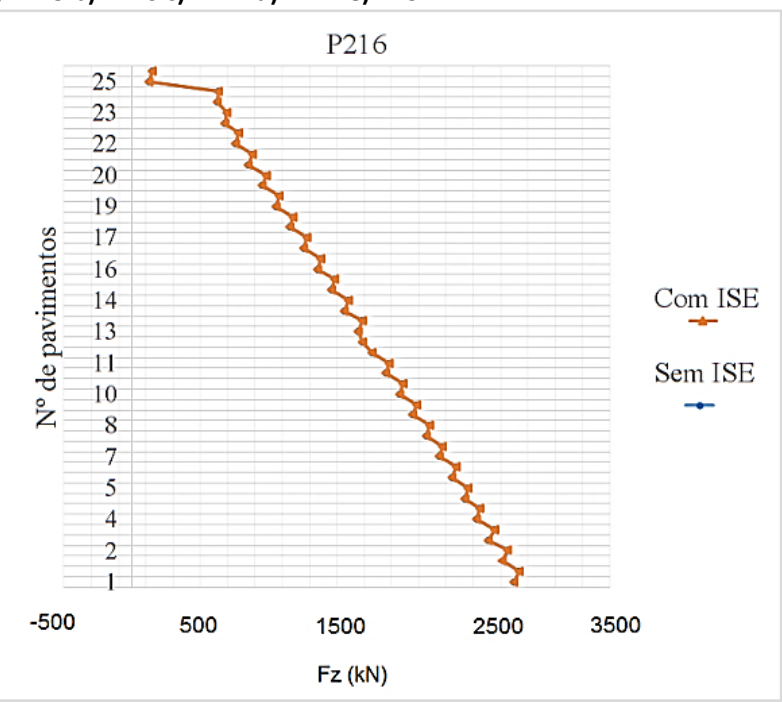

(b)

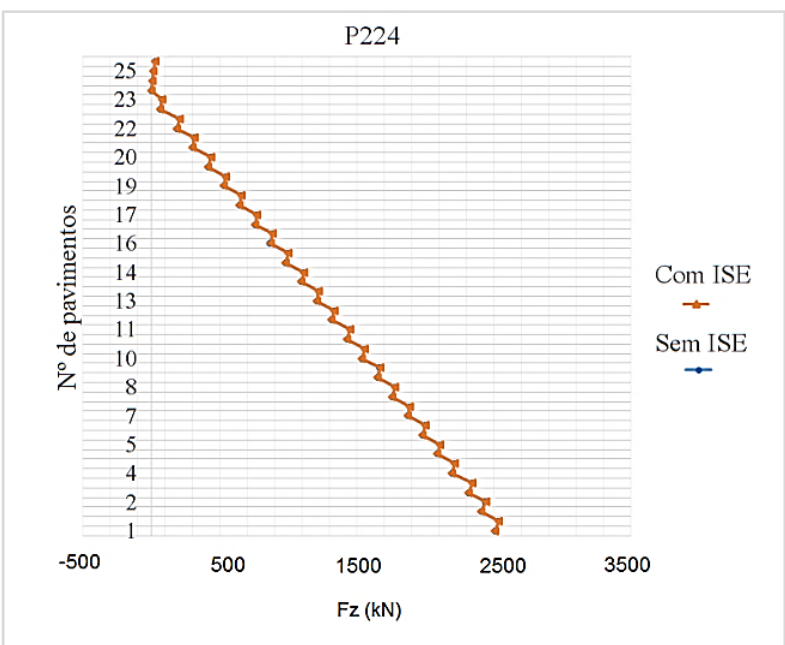

(d)

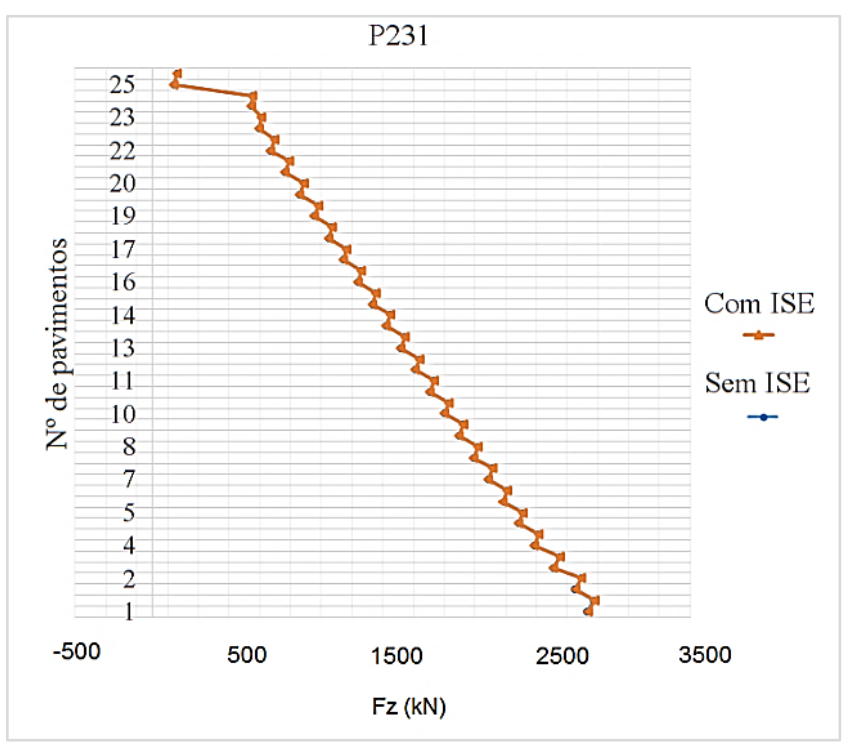

(e)

Fonte: Bahia (2015). 
BAHIA, G. de A. D.; CUNHA, R. P. da; MOTA, N. M. B.

Desempenho de edifícios altos com emprego da interação solo-estrutura

Figura 11 - Variação do $M_{x}$ antes e após a ISE para os pilares a) P215 b) P216 c) P221 d) P224 e) P231

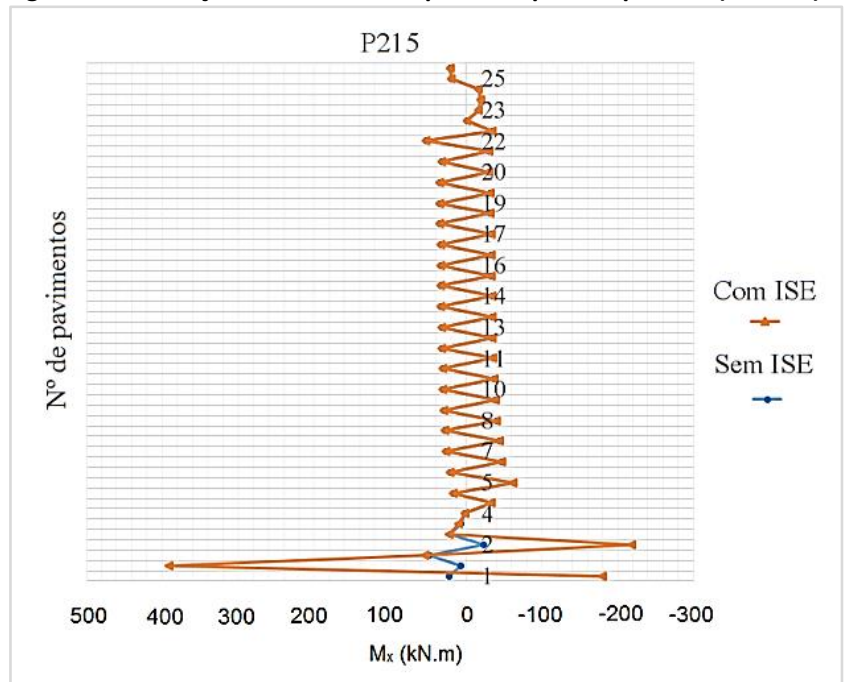

(a)

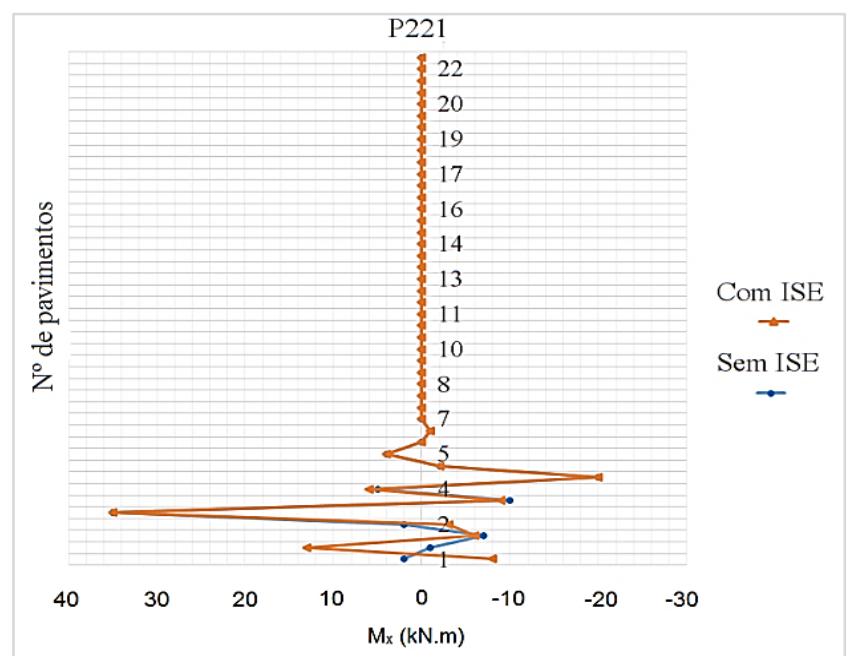

(c)

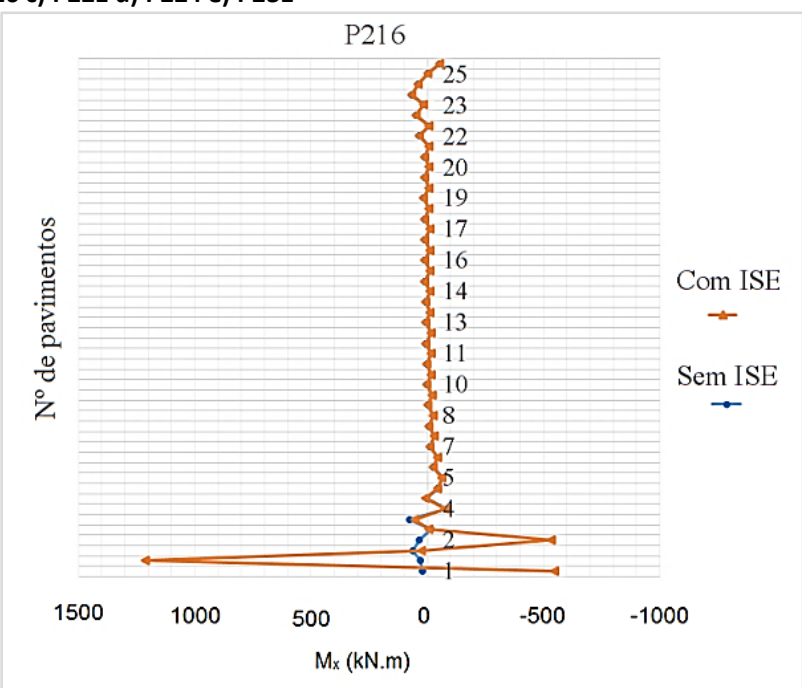

(b)

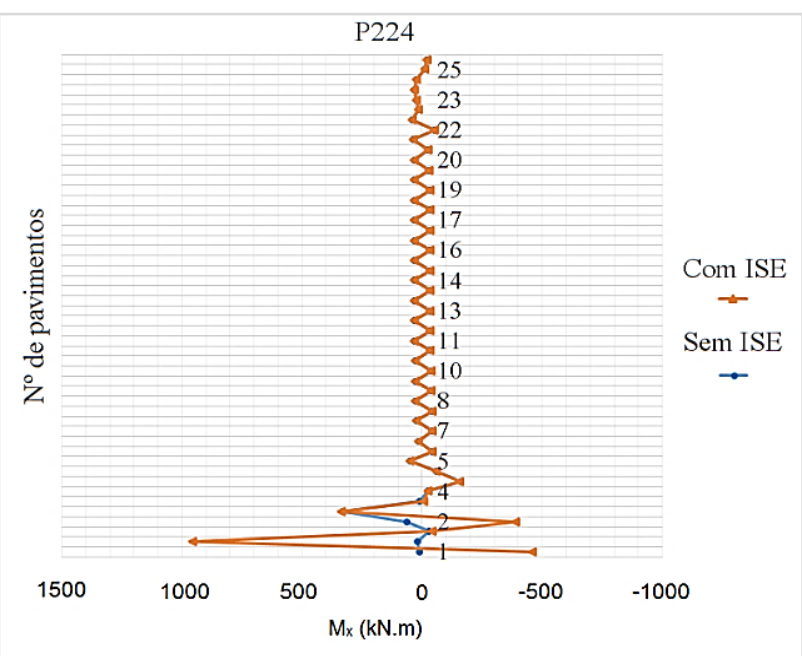

(d)

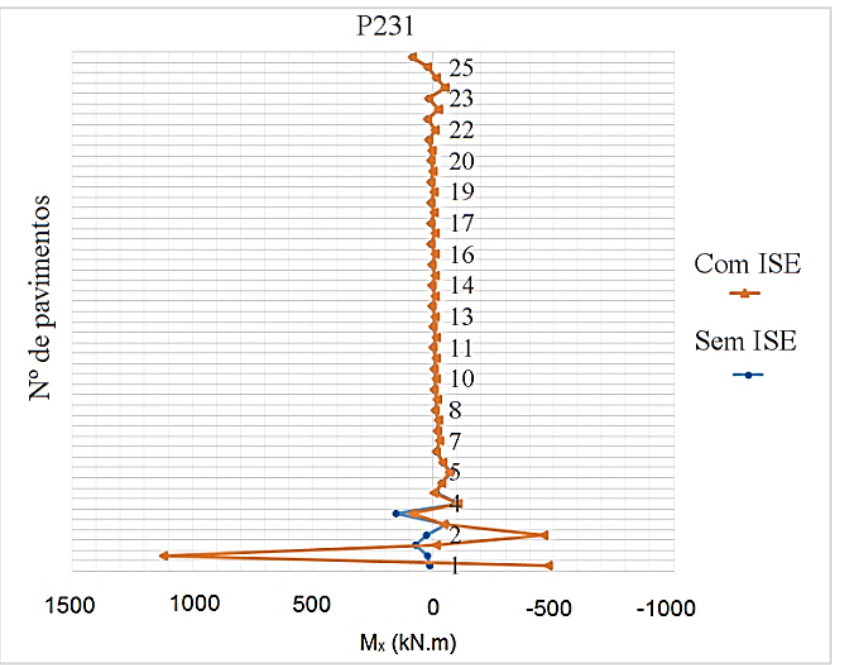

(e)

Fonte: Bahia (2015). 
BAHIA, G. de A. D.; CUNHA, R. P. da; MOTA, N. M. B.

Desempenho de edifícios altos com emprego da interação solo-estrutura

Figura 12 - Variação do $\mathrm{M}_{\mathrm{y}}$ antes e após a ISE para os pilares a) P215 b) P216 c) P221 d) P224 e) P231

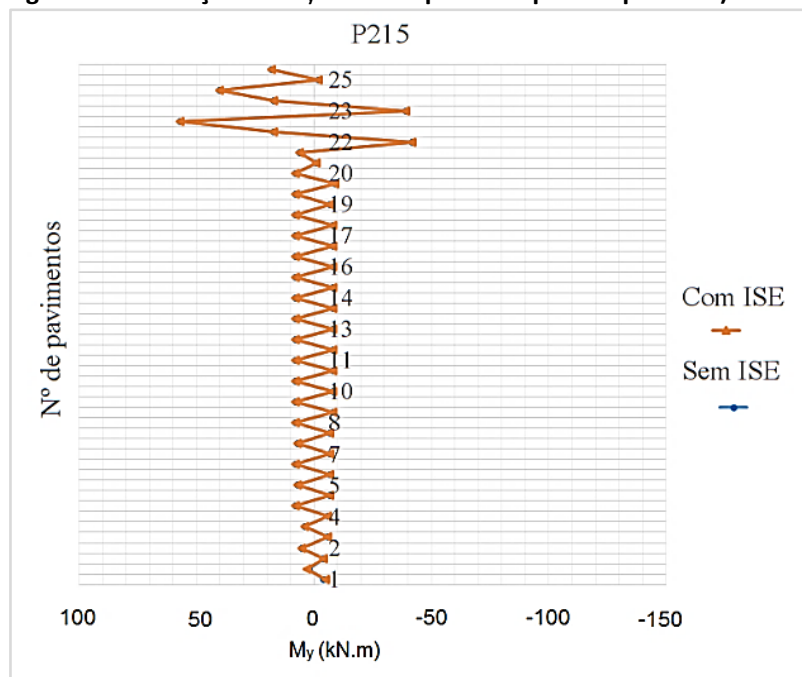

(a)

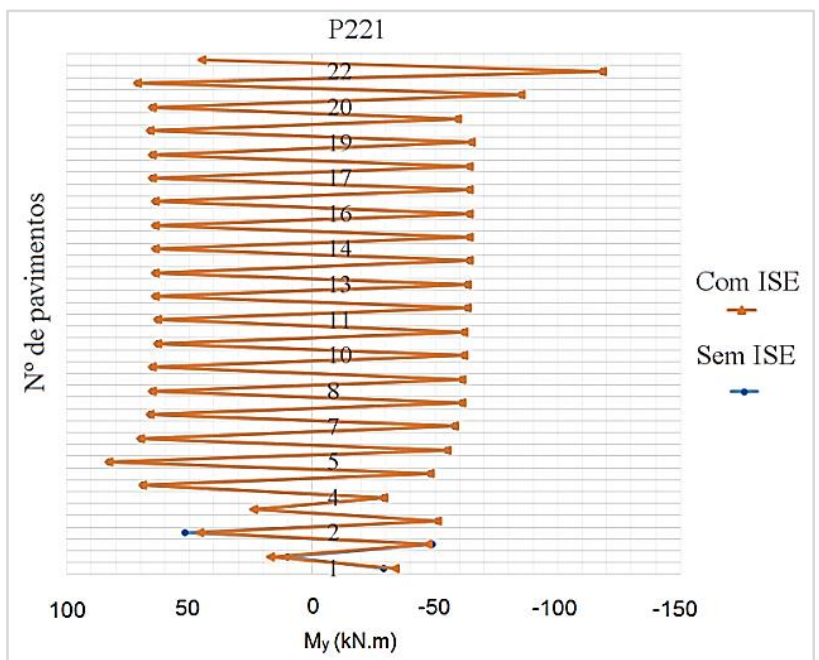

(c)

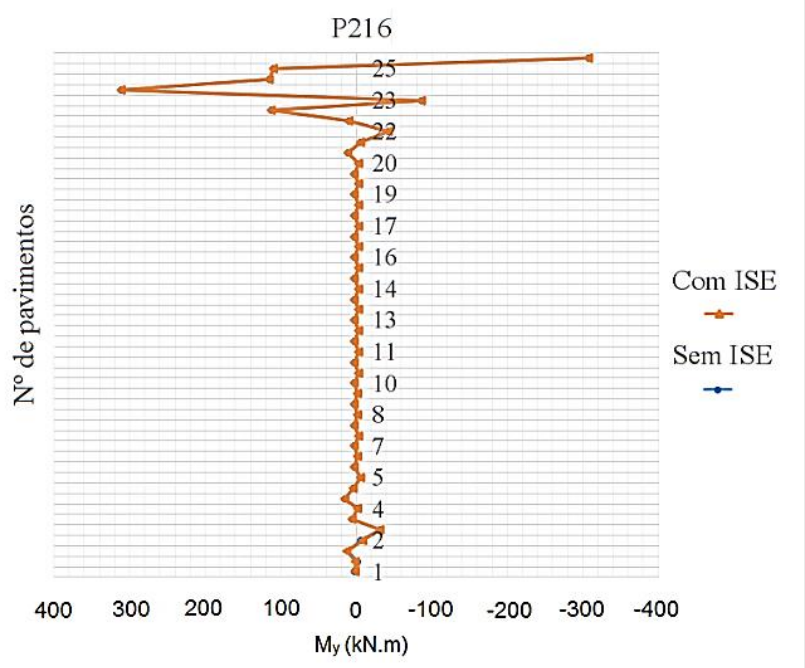

(b)

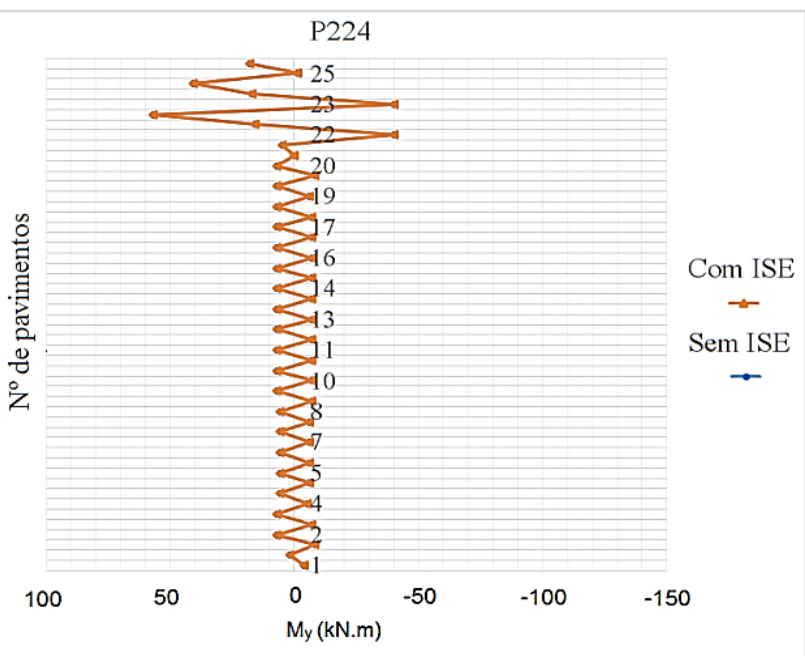

(d)

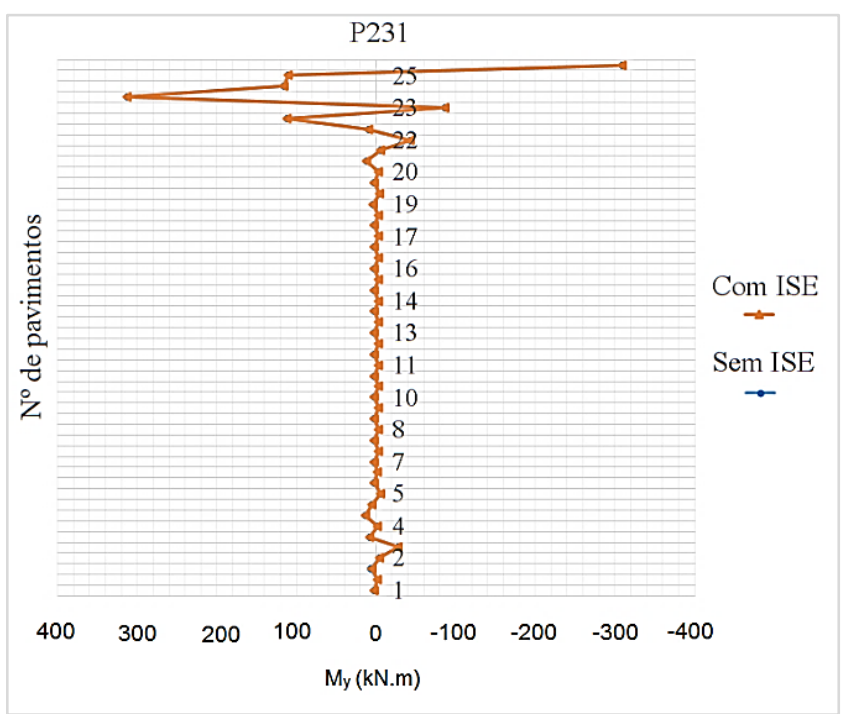

(e)

Fonte: Bahia (2015). 
BAHIA, G. de A. D.; CUNHA, R. P. da; MOTA, N. M. B.

A Tabela 7 apresenta a média da variação relativa de cada pilar para cada esforço analisado.

Tabela 7 - Média da variação relativa de cada pilar analisado

\begin{tabular}{cccc}
\multicolumn{2}{c}{ Tabela 7 - Média da variação relativa de cada pilar analisado } \\
Pilares & $\begin{array}{c}\text { Média da variação relativa } \\
\text { (\%) para } \mathbf{~ M x ~}\end{array}$ & $\begin{array}{c}\text { Média da variação } \\
\text { relativa (\%) para My }\end{array}$ & $\begin{array}{c}\text { Média da variação } \\
\text { relativa (\%) para Fz }\end{array}$ \\
\hline P215 & 111,42 & 1,5 & 0,005 \\
\hline P216 & 5,85 & $-4,15$ & $-0,009$ \\
\hline P221 & $-48,96$ & $-11,29$ & $-10,0$ \\
\hline P224 & $-26,40$ & 0 & 0,024 \\
\hline P231 & $-11,29$ & $-0,73$ & $-0,0005$ \\
\hline Fonte: Bahia (2015) & & &
\end{tabular}

Observa-se pela Tabela 7 que o esforço que obteve maior variação relativa média foi o $M_{x}$ seguido do $M_{y}$ e por último do $F_{z}$. Nota-se que essa variação nos valores de esforços antes e após a ISE atingiu até $111,42 \%$ para $0 M_{x}$, evidenciando que a diferença nos valores pode ser maior que o dobro do valor obtido por uma análise convencional.

A Figura 13 apresenta os resultados de recalques antes e após a consideração da interação solo-estrutura.

Figura 13 - Recalque com e sem ISE

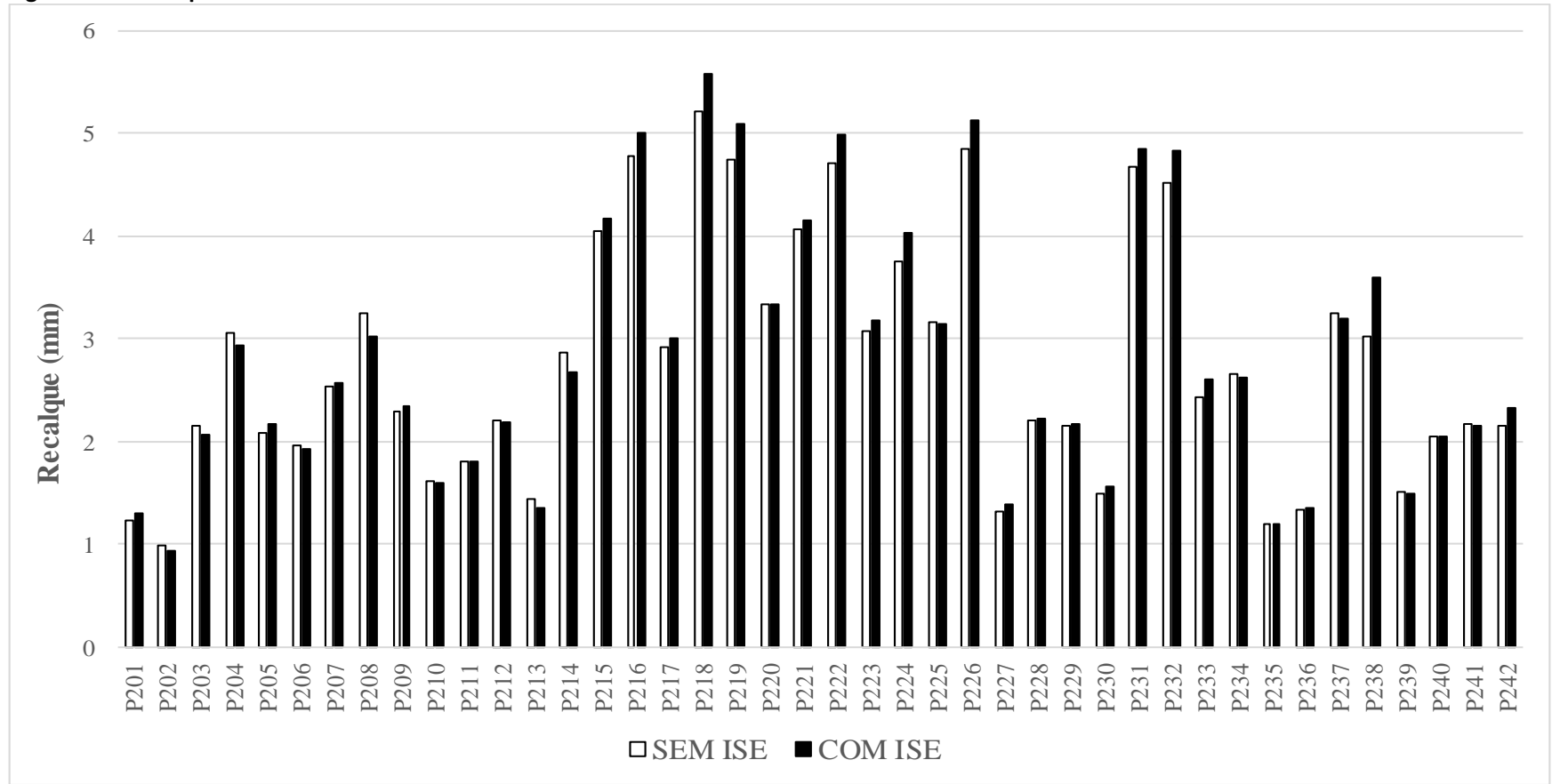

Fonte: Bahia (2015).

Os resultados de recalque apresentaram pouca variação nas situações com e sem ISE, sendo a média de variação entre o recalque obtido sem ISE para o recalque obtido com ISE de -0,073 mm, ou seja, na média os recalques com ISE estão maiores que os recalques sem ISE (Figura 13).

A Figura 14 apresenta a variação relativa dos recalques na consideração antes e após a ISE. Observa-se que a variação do recalque antes e após a ISE não ultrapassou $20 \%$ do recalque obtido sem ISE. A variação relativa negativa significa que o valor do recalque após a ISE foi menor que o recalque antes da ISE. De acordo com a Figura 14 a média da variação relativa foi de $1,91 \%$. 
BAHIA, G. de A. D.; CUNHA, R. P. da; MOTA, N. M. B.

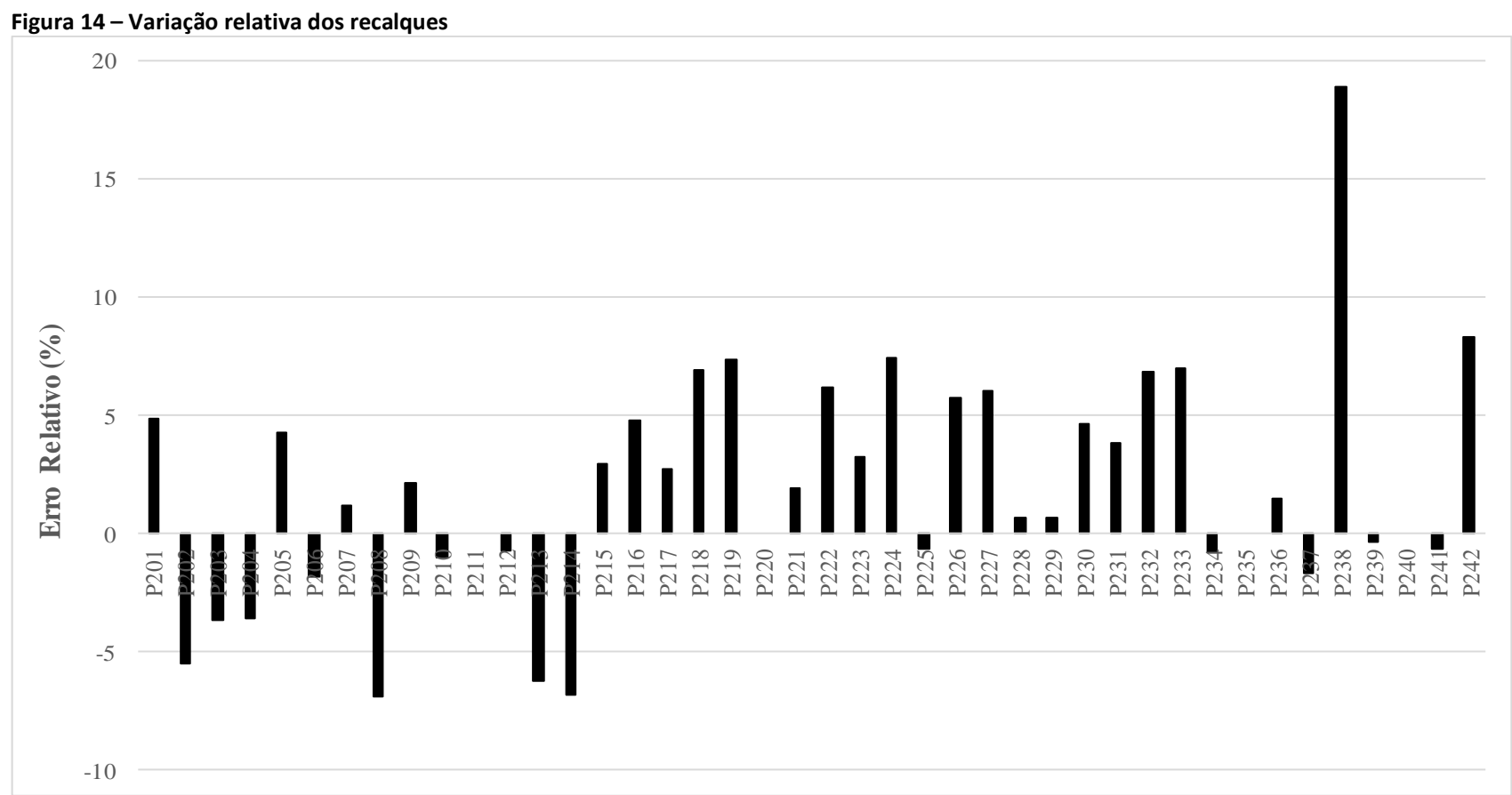

Fonte: Bahia (2015).

A Figura 15 apresenta os resultados dos recalques distorcionais antes e após a ISE. Observa-se que antes e após a ISE os recalques distorcionais se mantiveram dentro dos limites estabelecidos pelas bibliografias consagradas (1/500). Não houve variação do recalque distorcional após a análise.

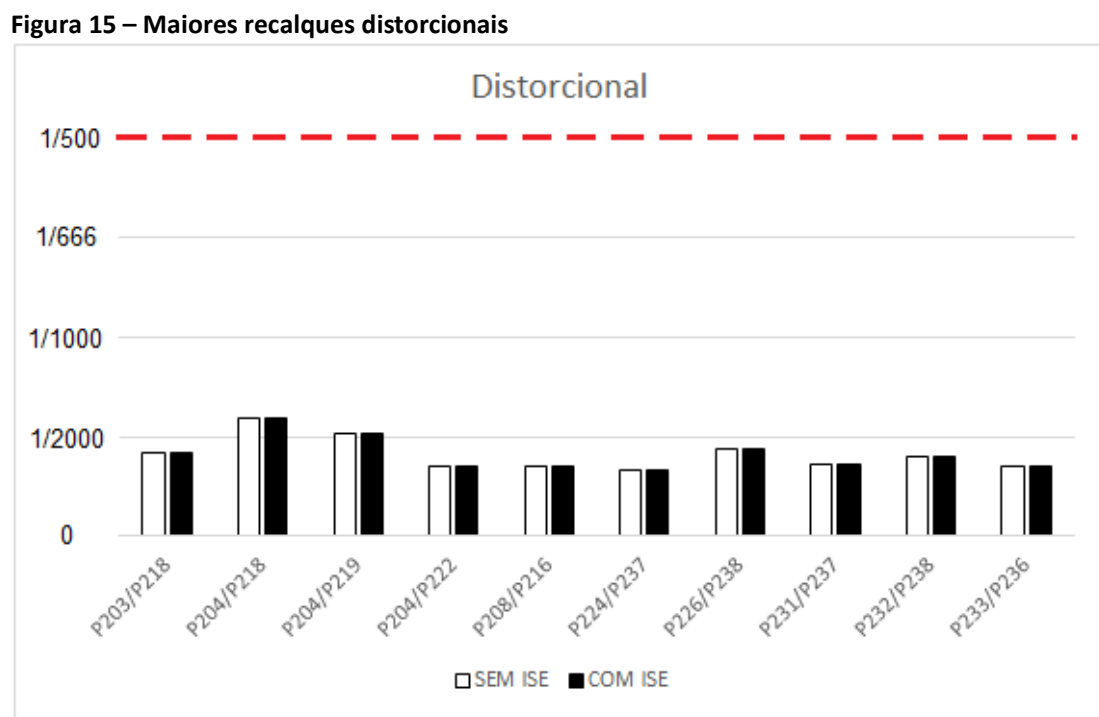

Fonte: Bahia (2015).

A Tabela 8 apresenta a variação relativa da análise com e sem a ISE com o monitoramento de recalques medido na estrutura. Observa-se que os valores de variação relativa foram altos, tanto para a análise sem ISE como para com ISE. Nota-se que não houve grande diferença entre as variações relativas para as duas análises em relação ao monitoramento de recalques. Destaca-se que os altos valores de dispersão obtidos se devem a baixa magnitude absoluta dos recalques, em que qualquer pequena diferença milimétrica equivale a um valor razoável de erro percentual. 
BAHIA, G. de A. D.; CUNHA, R. P. da; MOTA, N. M. B.

Desempenho de edifícios altos com emprego da interação solo-estrutura

Tabela 8 - Maiores recalques distorcionais

\begin{tabular}{ccc}
\hline Pilar & GARP Análise Sem ISE & GARP Análise Com ISE \\
\hline P209 & $-59,9$ & $-59,5$ \\
\hline P212 & $-54,3$ & $-54,3$ \\
\hline P218 & $-6,7$ & $-6,7$ \\
\hline P223 & $-25,6$ & $-25,6$ \\
\hline P225 & $-37,0$ & $-37,0$ \\
\hline P226 233 & $-28,4$ & $-28,5$ \\
\hline P234 & $-48,7$ & $-48,7$ \\
\hline P235 & $-49,1$ & $-49,1$ \\
\hline P237 & $-70,3$ & $-70,3$ \\
\hline P238 & $-30,3$ & $-30,3$ \\
\hline Média & $-18,2$ & $-18,2$ \\
\hline Desvio Padrão & $\mathbf{- 3 9 , 0}$ & $\mathbf{- 3 8 , 9}$ \\
\hline Coef. de & $\mathbf{1 9 , 2}$ & $\mathbf{1 9 , 2}$ \\
Variação & $\mathbf{- 4 9 , 3}$ & $\mathbf{- 4 9 , 3}$ \\
\hline
\end{tabular}

Fonte: Bahia (2015).

\section{Considerações finais}

Para o estudo de caso apresentado, de edifício alto, a diferença observada nas reações de apoio calculadas considerando a ISE e o cálculo convencional, no que diz respeito ao esforço cortante $F_{z}$, é evidente, porém sua magnitude é pequena e atinge apenas os pavimentos iniciais da edificação ( $5^{\circ}$ pavimento). A variação relativa média do esforço $F_{z}$ para os pilares analisados (P215, P216, P221, P224 e P231) foi de -2,0\%, dessa forma, seus valores são maiores, em geral, quando não é considerada a ISE, aos valores obtidos considerando os apoios indeslocáveis.

Quanto ao carregamento vertical da estrutura, observa-se que após a interação soloestrutura seus valores aumentam, porém, a magnitude é pequena, sendo a média da variação relativa de $1,91 \%$.

Com relação aos momentos fletores para os pilares ao longo da prumada da edificação houve uma considerável variação de esforços com e sem a ISE, em alguns casos até com a inversão dos momentos, porém essa variação ocorre apenas nos primeiros pavimentos da edificação, não atingindo andares superiores ao quinto. Para o momento fletor em $x$ a variação relativa média foi de $6,12 \%$, sendo a maior diferença de valores (Mx antes da ISE - Mx após a ISE) obtida para o P216 ao final do primeiro pavimento com -118,3kN.m e para o momento fletor em y a variação média foi de $-2,9 \%$, sendo a maior diferença de valores (My antes da ISE - My após a ISE) de -0,7kN.m. Dessa forma, observa-se que a média da variação relativa não retrata bem a magnitude do esforço que mais variou, isso se deve a presença de momentos negativos e positivos que na média acabam se anulando.

A variação de momentos que chegam às fundações tem seus valores maiores, em geral, quando considerada a ISE do que considerando os apoios indeslocáveis, sendo a média positiva apenas devido aos valores de momentos positivos ser maior na situação sem ISE do que na situação com ISE, em que predominam os valores negativos de momento.

Com isto, verifica-se que nas análises realizadas nesta dissertação foi obtida boa tendência dos resultados de esforços na estrutura, sendo observada a influência da ISE com mais evidência nos primeiros pavimentos, conforme Gusmão (1990) já havia constatado, quando afirmou existir um limite a partir do qual a ISE não exerceria mais grande influência no cálculo da edificação. 
Com relação à carga que a estrutura fornece, sabe-se que ela não representa a carga real da edificação, pois o concreto armado é um material heterogêneo, não elástico e de comportamento não linear, o cálculo das solicitações, no CAD/TQS, por meio da teoria da elasticidade, mesmo quando utilizado um modelo de pórtico espacial adequado não representa a carga real do edifício, sendo aconselhada a medição de cargas na estrutura para uma análise mais completa.

Com relação aos esforços obtidos na estrutura, observa-se que existe uma grande variação, especialmente no que se refere ao esforço $M_{x}$, quando se considera a ISE. A variação relativa média dos esforços $M_{x}, M_{y}$ e $F_{z}$, quando comparados aos esforços obtidos pela análise convencional, foi de $111,42,1,5 \%$ e 0,005\% para o P215, 5, 85\%, -4,15\% e -0,009\% para o $\mathrm{P} 216,-48,96 \%$, $-11,29 \%$ e $-10,0 \%$ para o $\mathrm{P} 221,-26,40 \%$, $0 \%$ e $0,024 \%$ para $\mathrm{p}$ P224 e -11,29\%-0,73\% e -0,0005\% para o P231.

Para a análise realizada, (utilizando a combinação de carregamento $\mathrm{PP}+\mathrm{G}$, considerando a não linearidade do modelo, as fases construtivas do nivelamento e da última medição de recalque), a média da variação relativa dos recalques foi de $-38,9 \%$, não sendo considerada satisfatória. Os altos valores das variações relativas de cada pilar podem ter sido ocasionados devido aos diversos parâmetros do solo que dependem da grande variabilidade estratigráfica e à simplificação realizada na flexibilização dos apoios realizadas no CAD/TQS que pode ter fornecido valores de esforços distantes dos reais.

Quanto aos recalques distorcionais, esta análise apresentou resultados satisfatórios estando todas as combinações de pilares com distorcionais dentro dos resultados das bibliografias consagradas. Sabe-se que a técnica de previsão de recalques é muito complexa e mesmo com todos os ajustes realizados os resultados não foram considerados satisfatórios.

No geral, observou-se que as maiores variações de carregamento foram encontradas nos primeiros pavimentos, fato também observado por Morosini, Navia e Cunha (2014) e Ritter et al. (2020). Vale ressaltar que a magnitude de variações de carregamento na estrutura e na deformada de recalques encontradas foi observada por se tratar de uma edificação com múltiplos pavimentos, ou seja, para edificações de até 8 pavimentos, as mudanças de carregamento e de recalque observados são irrelevantes.

Por fim, este trabalho apresenta uma contribuição na apresentação da metodologia e das análises de resultados que consideram a interação solo-estrutura em edifícios altos, bem como a importância da realização de provas de carga e instrumentação de obras, durante a construção, para a obtenção dos recalques de fundação.

\section{Agradecimentos}

Ao Conselho Nacional de Desenvolvimento Científico e Tecnológico (CNPq) pela bolsa de estudos de mestrado no Programa de Pós-Graduação em Geotecnia da UnB, Processo Nº 133357/2014-7.

\section{Referências}

ANTONIAZZI, Jiliana Pippi. Interação solo-estrutura de edifícios com fundações superficiais, 2011. 139f. Dissertação (Mestrado em Engenharia Civil) - Universidade Federal de Santa Maria, Santa Maria, 2011.

AOKI, Nelson. Discussion to session 14. In: INTERNATIONAL CONFERENCE ON SOIL MECHANICS AND FOUNDATION ENGINEERING. 12., 1989, Rio de Janeiro. Proceedings [...]. Rio de Janeiro: ICSMFE, 1989. p. 2963-2966, v. 5. 
ARAÚJO, Adrianne Carvalho de. Análise da interação solo-estrutura em edifícios sobre estacas. 2009. $144 \mathrm{f}$. Dissertação (Mestrado em Engenharias) - Universidade Federal de Goiás, Goiânia, 2009.

ARAÚJO, C. R. da S.; CARVALHO, E. M. L.; DANZIGER, B. R. Estudo das fundações de um caso de obra em estaca raiz envolvendo a interação solo x estrutura. ENGEVISTA, Rio de Janeiro, v. 14, n. 1, p. 104-123, 2012. DOI: https://doi.org/10.22409/engevista.v14i1.323.

BAHIA, Gabriela de Athayde Duboc. Avaliação do desempenho de fundações em edificação no DF com a utilização de técnicas de interação solo-estrutura. 2015. 266f. Dissertação (Mestrado em Geotecnia) - Universidade de Brasília, Brasília, 2015.

BARATA, Fernando Emmanuel. Recalques de edifícios sobre fundações diretas em terrenos de compressibilidade rápida e com a consideração da rigidez da estrutura. 1986. f.178. Tese (Concurso para Professor Titular) - Escola de Engenharia da Universidade Federal do Rio de Janeiro, Rio de Janeiro, 1986.

BORGES, Ana Cláudia Leão. Metodologia para avaliação do comportamento estrutural de edifícios altos em concreto armado com consideração da interação solo-estrutura. 2009. 205f. Tese (Doutorado em Engenharia Civil) - Universidade Federal de Pernambuco, Recife, 2009.

CAMPOS, Denise Vaz. Dimensionamento de blocos sobre estacas utilizando o conceito de radier estaqueado. 2011. 116f. Dissertação (Mestrado em Engenharias) - Universidade Federal de Goiás, Goiânia, 2011.

CHAMECKI, Samuel. Consideração da rigidez da estrutura no cálculo dos recalques da fundação. In: CONGRESSO BRASILEIRO DE MECÂNICA DOS SOLOS E ENGENHARIA DE FUNDAÇÕES, 1., 1954, Porto Alegre. Anais [...]. Porto Alegre: ABMS, 1954, p. 35-80, v. 1.

CORDEIRO, Ary Franck. Bahia. Avaliação numérica de reforço de grupo de estacas pela introdução de estacas adicionais. 2007. 118f. Dissertação (Mestrado em Geotecnia) - Universidade de Brasília, Brasília, 2007.

GONÇALVES, Juliana Cristina. Avaliação da influência dos recalques das fundações na variação de cargas dos pilares de um edifício. 2004. 126f. Dissertação (Mestrado em Engenharia Civil) - COPPE, Universidade Federal do Rio de Janeiro, Rio de Janeiro, 2004.

GOSHY, B. Soil-foundation-structure interaction. Journal of the Structural Division, v. 104, n. 5, p.749-761, 1978.

GUSMÃO, Alexandre Duarte. Estudo da interação solo estrutura e sua influência em recalques de edificações. 1990. 165f. Dissertação (Mestrado em Engenharia Civil) - COPPE, Universidade Federal do Rio de Janeiro, Rio de Janeiro, 1990.

GUSMÃO, A. D.; GUSMÃO FILHO, J. A. Um caso prático dos efeitos da interação solo-estrutura em edificações. In: CONGRESSO BRASILEIRO DE MECÂNICA DOS SOLOS E ENGENHARIA DE FUNDAÇÕES, 9., 1990, Salvador. Anais [...]. Salvador:ABMS, 1990, p. 437-446, v.2.

GUSMÃO FILHO, J. A. Fundações do conhecimento geológico à prática da engenharia. Recife: Editora Universitária, UFPE, 1998, $345 \mathrm{p}$.

HOLANDA JR, Osvaldo Gomes de. Interação solo-estrutura para edifícios de concreto armado sobre fundações diretas. 1998. 191f. Dissertação (Mestrado em Engenharia de Estruturas) - Escola de Engenharia de São Carlos, Universidade de São Paulo, São Carlos, 1998.

IWAMOTO, Roberto Kunihiro. Alguns aspectos dos efeitos da interação solo estrutura em edifícios de múltiplos andares com fundação profunda. 2000. 140f. Dissertação (Mestrado em Engenharia de Estruturas) - Escola de Engenharia de São Carlos, Universidade de São Paulo, São Carlos, 2000. DOI: https://doi.org/10.11606/D.18.2000.tde08062006-163117 
BAHIA, G. de A. D.; CUNHA, R. P. da; MOTA, N. M. B.

Desempenho de edifícios altos com emprego da interação solo-estrutura

JORDÃO, Darcília Ruan. Estabilidade global de edifícios sobre fundações profundas, considerando a interação estrutura-solo. 2003. 142f. Dissertação (Mestrado em engenharia civil) - Universidade de São Paulo, São Carlos DOI: https://doi.org/10.11606/D.18.2003.tde-23042008-100421

MEYERHOF, G. G. Some recent foundation research and its application to design. The Structural Engineer, v. 31, n. 6, p. 151-167, 1953. Disponível em: https://www.istructe.org/journal/volumes/volume-31-(published-in-1953)/issue6/some-recent-foundation-research-and-its-applicatio/. Acesso em: 5. Jan. 2021.

MOROSINI, Gustavo Marcos; NAVIA, João Paulo; CUNHA, José Mario Batista. Aplicação da interação solo-estrutura na análise de um edifício com fundações profundas - Estudo de caso. 2014. 59f. Trabalho de conclusão de curso (Engenharia de Produção Civil) - Universidade Tecnológica Federal do Paraná, Curitiba, 2014.

MOURA, Ana Regina Lima Uchôa de. Interação solo-estrutura em edifícios. 1995. 135f. Dissertação (Mestrado em Engenharia Civil) - Universidade Federal de Pernambuco, Recife, 1995.

POULOS, H. G. Settlement analysis of structural foundation systems. Sidney: School of Civil Engineering, University of Sydney, 1974, 32 p. (Research report - Res. Rpt. No. R-248 Monograph). Disponível em:

https://trid.trb.org/view/41207. Acesso em: 5 jan. 2021.

POULOS, H. G. Modified calculation of pile group settlement interaction. Journal of Geotechnical Engineering, ASCE, vol. 114, no. 6, 697-705, 1998.

RITTER, M. G. et al. Análises de interação solo-estrutura em edifícios com fundação profunda. Rev. IBRACON Estrut. Mater., São Paulo, v. 13, n. 2, p. 248-273, Apr. 2020 DOI: http://dx.doi.org/10.1590/s1983-41952020000200005

SALES, Maurício Matines. Análise do comportamento de sapatas estaqueadas. 2000. 229f. Tese (Doutorado em Engenharia Civil) - Universidade de Brasília. Brasília, 2000.

SOARES, José Moura. Estudo numérico-experimental da interação solo-estrutura em dois edifícios do Distrito Federal. 2004. 265f. Tese (Doutorado em Geotecnia) - Universidade de Brasília, Brasília, 2004.

\footnotetext{
${ }^{1}$ Gabriela de Athayde Duboc Bahia

Engenheira Civil. Mestre em Geotecnia. Professora Adjunta no Centro Universitário de Brasília. Endereço postal: Campus da Asa Norte: SEPN 707/907 - Campus Universitário, ICPD, Brasília, DF, Brasil, 70.790-075

\section{${ }^{2}$ Renato Pinto da Cunha}

Engenheiro Civil. Doutor em Geotecnia. Professor Titular na Universidade de Brasília, Faculdade de Tecnologia, Departamento de Engenharia Civil e Ambiental. Endereço postal: Campus Universitário Darcy Ribeiro, SG12, Brasília, DF, Brasil, 70.910-900

\section{${ }^{3}$ Neusa Maria Bezerra Mota}

Engenheira Civil. Doutora em Geotecnia. Professora Titular no Centro Universitário de Brasília, Departamento de Engenharia Civil. Endereço postal: Campus da Asa Norte: SEPN 707/907 - Campus Universitário, ICPD, Brasília, DF, Brasil, 70.790-075
} 